\title{
Circulations, Bounded Weak Echo Regions, and Horizontal Vortices Observed within Long-Lake-Axis-Parallel-Lake-Effect Storms by the Doppler on Wheels*
}

\author{
Scott M. Steiger, Robert Schrom, Alfred Stamm, Daniel Ruth, Keith JaszKa, \\ TIMOTHY KRESS, AND BRETT RATHBUN \\ Department of Earth Sciences, State University of New York at Oswego, Oswego, New York \\ JEFFREY FRAME \\ Department of Atmospheric Sciences, University of Illinois at Urbana-Champaign, Urbana, Illinois \\ JOSHUA WURMAN AND KAREN KOSIBA \\ Center for Severe Weather Research, Boulder, Colorado
}

(Manuscript received 6 August 2012, in final form 15 January 2013)

\begin{abstract}
The eastern Great Lakes (Erie and Ontario) are often affected by intense lake-effect snowfalls. Lake-effect storms that form parallel to the major axes of these lakes can strongly impact communities by depositing more than $100 \mathrm{~cm}$ of snowfall in less than $24 \mathrm{~h}$. Long-lake-axis-parallel (LLAP) storms are significantly different in structure and dynamics compared to the much more studied wind-parallel roll storms that typically form over the western Great Lakes. A Doppler on Wheels (DOW) mobile radar sampled several of these storms at fine spatial and temporal resolutions (and close to the surface) during the winter of 2010-11 over and downwind of Lake Ontario to document and improve understanding of how these storms develop. Over 1100 observations of vortices were catalogued within the 16 December 2010 and 4-5 January 2011 events. The majority of these vortices were less than $1 \mathrm{~km}$ in diameter with a statistical modal difference in Doppler velocity (delta-V) value across the vortex of $11 \mathrm{~m} \mathrm{~s}^{-1}$. Vortices developed along boundaries, which formed within the bands, suggesting horizontal shear instability was the main cause. Other features noted in the DOW observations included bounded weak echo regions, anvils, and horizontal vortices, typically on the south side of west-eastoriented LLAP bands. The reflectivity and velocity structure of LLAP bands were found to be much more complex than previously thought, which may impact localized precipitation amounts and errors in forecast location/intensity.
\end{abstract}

\section{Introduction}

The eastern Great Lakes region experiences some of the most intense snowstorms in the world. Lake-effect snowstorms, which form parallel to the wind and long axis of a Great Lake, termed long-lake-axis-parallel (LLAP) bands in this study, can produce substantial

\footnotetext{
* Supplemental information related to this paper is available at the Journals Online website: http://dx.doi.org/10.1175/MWRD-12-00226.s1.

Corresponding author address: Scott Steiger, 206 Hewitt Union, Department of Earth Sciences, State University of New York at Oswego, Oswego, NY 13126.

E-mail: scott.steiger@oswego.edu
}

snowfall rates and total storm accumulations $\left(>8 \mathrm{~cm} \mathrm{~h}^{-1}\right.$ and $>130 \mathrm{~cm}$, respectively). Niziol et al. (1995) give a thorough description of these severe local storms (type 1 in their paper), which occasionally become electrified with significant lightning production indicating the relatively intense vertical motions within these winter storms (Moore and Orville 1990). It is difficult to forecast the initiation, demise, changes in location, and intensity of these narrow storms (typical width $<40 \mathrm{~km}$ ). Indeed, Ballentine and Zaff (2007) show that the Weather Research and Forecasting (WRF; Skamarock et al. 2008) modeling system has significant errors in forecasting band characteristics between 6 and $36 \mathrm{~h}$ after model initialization. In their study, the simulated band location has a persistent southward bias for both model cores [Nonhydrostatic Mesoscale Model (NMM) and 
Advanced Research WRF (ARW)] by about $14 \mathrm{~km}$. The current lack of understanding of the basic microphysics and dynamics of these storms has likely led to frequent forecast errors.

LLAP bands have a different structure compared to the wind-parallel rolls (WPR) generally associated with the western Great Lakes (e.g., Kelly 1982). Kristovich and Steve (1995) show that LLAP-type bands (called shore-parallel bands in their study) are more frequent over Lakes Erie and Ontario, likely because the prevailing wind direction (westerly) occurring when lakeinduced instability is high during the cold season is largely parallel to the major axes of these lakes. Indeed, $32 \%$ of lake-effect cases over Lake Ontario are of the LLAP type, while only $\sim 10 \%$ of lake-effect cloudiness over the western lakes of Superior, Michigan, and $\mathrm{Hu}-$ ron is associated with these intense storms. The eastern Great Lakes average about seven LLAP events per cool season while the western Great Lakes only average four (Kristovich and Steve 1995). Lake-effect storm research has been dominated by field studies over the western Great Lakes (e.g., Kristovich et al. 2000 and references therein); greater study is warranted of the generally more intense LLAP storms that can affect a significant population (e.g., the Interstate 90 corridor between Cleveland, Ohio, and Syracuse, New York) when contrasted with the WPR-type bands.

The LLAP band, as focused on in this study, has similarities, but is also different in character from the lake-effect storms discussed by Passarelli and Braham (1981) and Hjelmfelt (1992). The "shoreline parallel" and "midlake" bands discussed by these studies and further investigated by Laird et al. (2003) are heavily dependent on the formation of well-developed land breezes and their low-level convergence fields. Land breezes, which form in response to the surface air over the lake being much warmer (by $\sim 10^{\circ} \mathrm{C}$ ) than the surrounding land, likely play a part in the morphology of the LLAP storm, but are usually superimposed on a significant synoptic-scale westerly low-level flow $\left(>10 \mathrm{~m} \mathrm{~s}^{-1}\right.$; Niziol 1987) for storms over the eastern Great Lakes. This situation leads to a lake-scale confluence zone that aids in the development of a single, intense snowband forming over the middle of Lake Ontario or along its southern shoreline. It is difficult to determine how much of the low-level convergence over the lake during a lakeeffect event is due to a band-induced circulation [e.g., Ballentine et al. 1998; and seen in WRF simulations run locally at State University of New York (SUNY) Oswego] versus the broader land breezes forming along the northern and southern shores of Lake Ontario and converging over the lake. Future field research may help answer this problem.
Ground-based Weather Surveillance Radar-1988 Dopplers (WSR-88Ds) often overshoot the relatively shallow boundary layer convection that occurs over the Great Lakes. This is especially true for the nearest radar to the eastern Lake Ontario region in Montague, New York (KTYX), positioned $40 \mathrm{~km}$ inland on the Tug Hill Plateau (elevation $562 \mathrm{~m} \mathrm{MSL}$; $>450 \mathrm{~m}$ above the lake surface). Therefore, Doppler on Wheels (DOW; Wurman et al. 1997; Wurman 2001) mobile dual-polarized radar and rawinsonde data were collected to improve the understanding of the structure and microphysical processes within LLAP-lake-effect storms. This was a demonstration project for the X-band (3-cm wavelength) DOW as it has seen limited use in lake-effect snow conditions and in the topography characteristic of upstate New York (many hills and trees). The DOW is also able to collect data at much finer-scale resolution and much closer to the ground than the nearby WSR-88Ds [Buffalo, New York (KBUF), and KTYX]. Surface and upper-air data within and near these storms were also collected by a team of 10 undergraduate research assistants with a Vaisala, Inc., rawinsonde system and probe trucks provided by the Center for Severe Weather Research (CSWR), which measured standard meteorological variables (temperature, relative humidity, pressure, and wind) as they transected the bands.

The main objectives of this research are twofold: 1) to document the finescale structure of lake-effect snow storms in upstate New York and 2) to examine the microphysical processes that occur within LLAP-lake-effect storms. Results related to the first objective are discussed in this paper while those related to the second objective will be discussed in a future paper.

\section{Background on Lake Ontario long-lake-axis- parallel-lake-effect storms}

One of the distinct mesoscale features of the LLAP snowbands that frequently form over Lake Ontario during a lake-effect event is the presence of a low-level [ $(0.1-0.5 \mathrm{~km})$ AGL $]$ convergence zone, in which inflow from both sides of the band meet (Peace and Sykes 1966; Ballentine et al. 1998). These storms also have divergent flow at upper levels above the mesoscale updraft (storm top typically near $2-3 \mathrm{~km}$ AGL) and a warm-core structure owing to sensible heating of the converging surface air parcels by the relatively warm lake and latent heating due to condensation and freezing as the parcels ascend.

The Lake Ontario Winter Storms (LOWS; Reinking et al. 1993) project used a dual-polarized X-band (3.2-cm wavelength) radar situated east of the lake, a Radio Acoustic Sounding System (RASS), three wind profilers, 
TABLE 1. Lake-effect events sampled by the Doppler on Wheels radar in 2010-11.

\begin{tabular}{|c|c|c|}
\hline Event date & $\begin{array}{l}\text { DOW locations (refer to Figs. } 2 \\
\text { and } 4 \text { for * events) }\end{array}$ & Notes \\
\hline *15-16 Dec 2010 & Fairhaven and Oswego, NY & $\begin{array}{l}\text { Shoreline locations; cellular to LLAP transition; sampled a few periods during } \\
\text { 1935-1719 UTC; two soundings launched }\end{array}$ \\
\hline 3 Jan 2011 & Williamstown, NY & $\begin{array}{l}\text { Inland locations; broken band to LLAP transitions; sampled 0040-1912 UTC; } \\
\text { one sounding }\end{array}$ \\
\hline *4-5 Jan 2011 & Fairhaven, NY & $\begin{array}{l}\text { Shoreline location; intense LLAP band with lightning and vortices; sampled } \\
\text { 2056-0510 UTC; four soundings }\end{array}$ \\
\hline 5 Jan 2011 & Northern Orleans County, NY & $\begin{array}{l}\text { Shoreline location; Lake Huron-to-Ontario connection; sampled } \\
\text { 1756-2000 UTC }\end{array}$ \\
\hline 6 Jan 2011 & Fairhaven, NY & Shoreline location; sampled 0008-0710 UTC; three soundings \\
\hline 15-16 Jan 2011 & $\begin{array}{l}\text { North of Pulaski, NY, Oswego } \\
\text { and Fairhaven }\end{array}$ & Shoreline locations; broken band; sampled 2110-0735 UTC; four soundings \\
\hline 10 Feb 2011 & Oswego, NY & $\begin{array}{l}\text { Shoreline location; LLAP band mostly } \sim 25 \mathrm{~km} \text { north of DOW over lake; } \\
\text { sampled } 0125-1700 \text { UTC; four soundings }\end{array}$ \\
\hline
\end{tabular}

* Events discussed in this paper.

and mobile sounding equipment to study lake-effect storms from January to March 1990. The analysis from the LOWS project is limited to only one LLAP-type event and a discussion of the dual-polarimetric characteristics in lake-effect storms is not found in the literature until recently (Cermak et al. 2012; Ahasic et al. 2012). The height of the capping inversion (i.e., depth of the boundary layer) is shown to be a better predictor of band strength than the degree of instability (e.g., the lake surface to $850-\mathrm{hPa}$ temperature difference) according to the LOWS results. Another important finding during the LOWS project is the occurrence of wind maxima (jets) near and within the band based on radar observations. The winds were slower in the core of the band, but jets appeared near $1 \mathrm{~km}$ AGL with speeds approaching $20 \mathrm{~m} \mathrm{~s}^{-1}$ just outside the core.

There have been many more studies of lake-effect storms that form over the western Great Lakes [e.g., the Lake-Induced Convection Experiment (Lake-ICE) experiment described by Kristovich et al. (2000)] and of seaeffect storms that form over the Sea of Japan (e.g., Inoue et al. 2011), but the character of these storms differ significantly compared to LLAP bands. Generally, the WPR storms are horizontal convective rolls (HCRs) and form in a multiband configuration over the western Great Lakes as the winds typically cross the short axes of the lakes during cold-air outbreaks. The sea-effect storms that form near Japan shown by Inoue et al. (2011) have more cell-like features in comparison to the more continuous (in radar reflectivity) mesoscale LLAP bands.

\section{Methodology}

\section{a. Data collection}

The DOW sampled seven events during the 2010-11 field campaign of this study (Table 1). The DOW is an
X-band dual-polarimetric, dual-frequency system (see Wurman et al. 1997; Wurman 2001; and Table 2 for a description). For the two cases discussed within this paper (15-16 December 2010 and 4-5 January 2011), the DOW performed sector scans over the lake from near west to east-northeast of the radar $\left(\sim 150^{\circ}\right.$ sector $)$. The plan position indicator (PPI) elevation angles were between $1^{\circ}$ and $11^{\circ}$ (in $1^{\circ}$ increments) and range height indicator scans (RHIs) were performed every $3 \mathrm{~min}$ approximately perpendicular to the band. Note the other two LLAP events (3 January and 10 February 2011) are not presented in this paper because of time constraints and will be part of future research.

Rawinsondes were launched within and near $(<10 \mathrm{~km})$ the lake-effect storms with the Vaisala DigiCORA Sounding System MW31 (RS92 sondes). The purpose was to observe the structure of the boundary layer (depth, humidity, and wind shear) in which these storms formed. These observations aided in the development of hypotheses for some of the radar observations in this study (e.g., why one case had many more vortices than the other).

\section{b. Analysis and techniques}

The DOW data were analyzed using the National Center for Atmospheric Research (NCAR) Solo-II

TABLE 2. Doppler on Wheels (DOW 7) specifications.

\begin{tabular}{ll}
\hline \hline Half-power beamwidth & $0.93^{\circ}$ \\
Frequency 1 & $9.50 \mathrm{GHz}$ \\
Frequency 2 & $9.35 \mathrm{GHz}$ \\
Gate length & $60 \mathrm{~m}$ \\
Transmitter pulse & $0.46 \mu \mathrm{s}$ \\
Dual-polarization mode & $\mathrm{T} / \mathrm{R}$ simultaneous, \\
& process separately \\
Transmitter power & $250 \mathrm{~kW}$ \\
\hline
\end{tabular}


software (Oye et al. 1995). A significant finding during the initial analysis of the data was the frequent occurrence of vortices on the miso- $(40-4000 \mathrm{~m})$ to meso(4-400 km) scales (Fujita 1981) embedded along the length of a lake-effect snowband. The vortices were subjectively diagnosed by their size ( $D$; the distance between the Doppler velocity extremes), strength (delta-V; the Doppler velocity difference across the vortex), duration, implied vertical vorticity, and location in the band. The Mesocyclone Detection Algorithm (Stumpf et al. 1998), from which our subjective vortex detection is based, has a minimum delta- $\mathrm{V}$ threshold of $10 \mathrm{~m} \mathrm{~s}^{-1}$. Since lake-effect snowstorms have significantly weaker updrafts compared with supercell thunderstorms, we used a lower delta- $\mathrm{V}$ threshold of $5 \mathrm{~m} \mathrm{~s}^{-1}$. To be considered a vortex, the velocity couplet had to exhibit a delta- $\mathrm{V}$ of at least $5 \mathrm{~m} \mathrm{~s}^{-1}$ and had to be detected by the radar for at least $5 \mathrm{~min}$ (two consecutive scans at the same elevation angle). All data analyzed were within $50 \mathrm{~km}$ of the DOW, which reduced data degradation due to range effects and beam spreading so it was not necessary to have the delta- $V$ threshold vary with range. Doppler velocity couplets that were evident at multiple consecutive elevation angles in a sector volume scan were considered part of the same vortex if they implied the same sense of rotation (cyclonic-anticyclonic) and were within $2 \mathrm{~km}$ of the lowest couplet (a simplified version of the 3D method used by Stumpf et al.). The majority of vortices were visible only in the lowest two elevations.

The detectability of vortices, and the magnitude of measured delta- $\mathrm{V}$ across the vortices, are expected to vary with range. A 1-km diameter vortex (from peak outbound to peak inbound Doppler velocity) would barely be detectable at $50 \mathrm{~km}$, since the gates would be spaced $\sim 1 \mathrm{~km}$ apart. But that vortex's measured delta-V would be substantially reduced. Since corrections for these possible range effects (see section $5 \mathrm{~b}$ ) had minimal impact we decided to show raw measurements of the vortex diameter and strength (delta-V) in this study.

Vortex characteristics were measured at the elevation angle of greatest strength and/or organization of the vortex in each sector volume scan. Organization was defined as the presence of a distinct Doppler velocity couplet (adjacent maxima of Doppler velocities of opposite signs or adjacent maximum and minimum values if the velocity was the same sign because storm-relative velocity was not calculated). Tracking each vortex was based on the assumption that a feature would move no more than $3 \mathrm{~km}$ downstream between two radar sweeps at the same elevation. Each sector scan was about $3 \mathrm{~min}$ or $180 \mathrm{~s}$ in duration. Mean west-northwesterly $10 \mathrm{~m} \mathrm{~s}^{-1}$
850-hPa winds were present throughout the two events analyzed in this paper. The $850-\mathrm{hPa}$ level was typically in the core elevation of a lake-effect band and is used by forecasters to predict band location (Niziol et al. 1995). Hence, radar features were expected to be advected $1.8 \mathrm{~km}$ during a sector scan in this study. However, $3 \mathrm{~km}$ was used as the threshold to account both for the magnitude of the advection by the 850 -hPa background flow and potential propagation of a vortex.

\section{Results}

\section{a. Overview of the 15-16 December 2010 and 4-5 January 2011 events}

Some of the most unique DOW observations were made during the 15-16 December 2010 and 4-5 January 2011 events. The 15 December 2010 lake-effect storm developed within northwest flow with 850 -hPa temperatures near $-15^{\circ} \mathrm{C}$ (Fig. 1a). The short fetch over Lake Ontario resulted in a multiband storm centered in southern Oswego County (see Fig. 2; Oswego, New York, is in Oswego County). The winds became more westerly during the morning of 16 December 2010 as the 850-hPa low pressure system center retrograded to the north of Lake Ontario by 1600 UTC 16 December (Fig. 1c). Even though the $850-\mathrm{hPa}$ temperatures warmed to near $-12^{\circ} \mathrm{C}$, the lake-effect storm intensified into a single band because of the greater fetch between 0600 and 1600 UTC 16 December (see Figs. 2b,c) with maximum radar reflectivity values near $35 \mathrm{dBZ}$ according to the WSR-88D in Montague, New York (KTYX). Between 2000 UTC 15 December and 1300 UTC 16 December, the DOW sampled the storm from north and east of the band at Fair Haven, New York (Figs. 2a,b), and from the south of the intense band at Oswego between 1400 and 1700 UTC 16 December (Fig. 2c). The storm continued after 1700 UTC 16 December as conditions remained favorable for lake-effect convection (see Figs. 1d and $2 \mathrm{~d}$ ), but because of crew fatigue, operations ended at 1700 UTC.

The 4-5 January 2011 event developed under marginal boundary layer instability with $850-\mathrm{hPa}$ temperatures near $-9^{\circ} \mathrm{C}$ (Fig. 3a). The lake surface temperature was approximately $5^{\circ} \mathrm{C}$, leading to a temperature difference of $14^{\circ} \mathrm{C}$, just above the instability threshold $\left(13^{\circ} \mathrm{C}\right)$ for the development of significant lake-effect convection typically used by forecasters as given by Holroyd (1971). However, it was a deep, moist boundary layer with the lowest base of an absolutely stable layer near $600 \mathrm{hPa}$ according to a sounding launched at Oswego at 2156 UTC 4 January (not shown). The winds were well aligned (parallel at multiple levels within the 

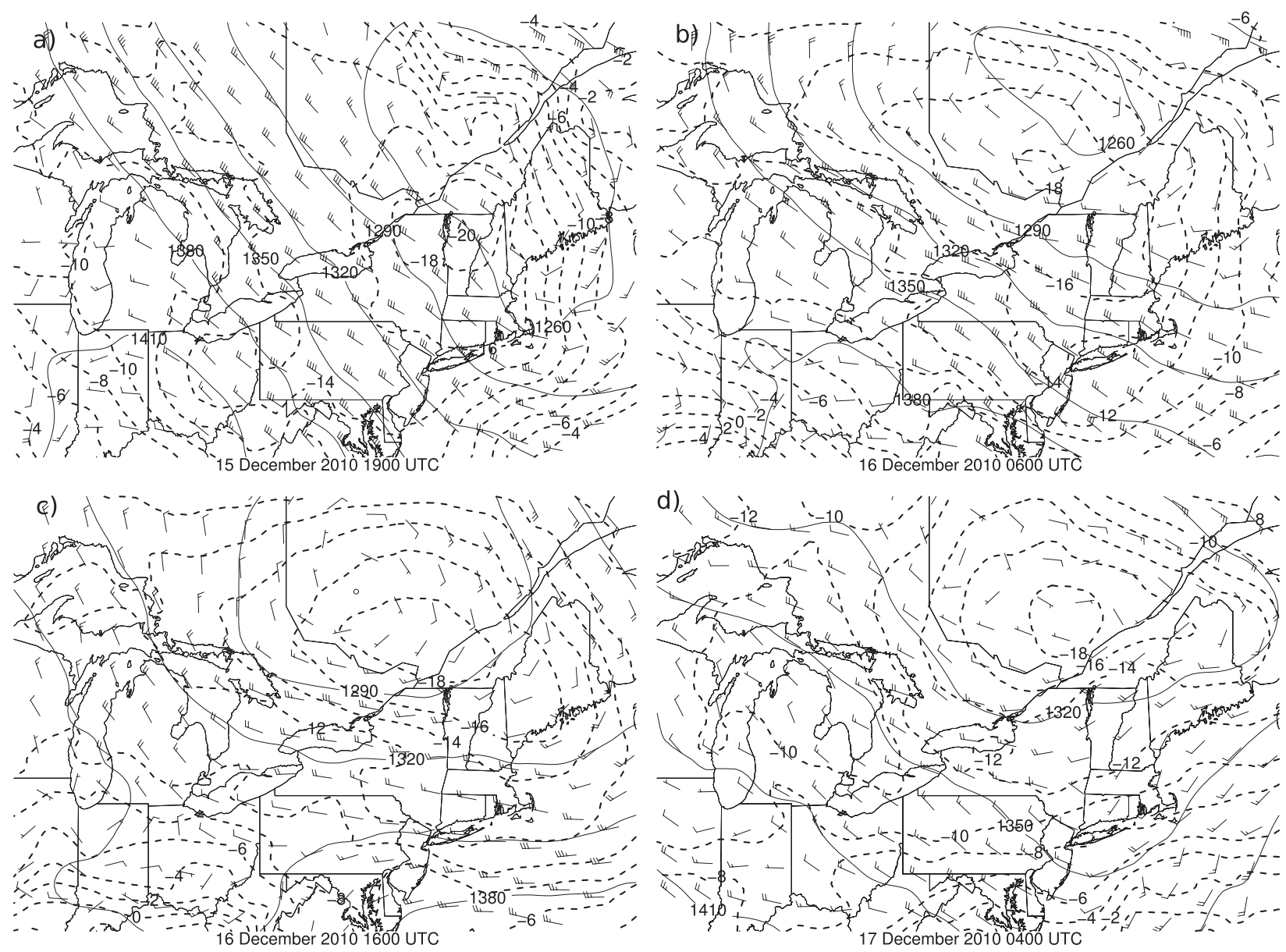

FIG. 1. (a)-(d) RUC model initial analyses of 850 -hPa height (m), temperature $\left({ }^{\circ} \mathrm{C}\right)$, and wind barbs $(\mathrm{kt})$ across the Great Lakes region for specified times during the 15-16 Dec 2010 lake-effect event.

boundary layer) from the west-northwest for the initial $6 \mathrm{~h}$ of the event, which led to the development of an intense LLAP band as seen in Figs. 4a,b. There were several reports of lightning and thunder by the SUNY Oswego student researchers at the campus during this time. The $850-\mathrm{hPa}$ winds veered to northwesterly by 0400 UTC 5 January, as a trough deepened along the northeast coast of the United States (Fig. 3c). The lakeeffect band shifted south during this transition with the development of a mesoscale vortex as observed by the KTYX radar in Fig. 4c (note the hook shape in radar reflectivity just north of Fair Haven, where the DOW was located throughout the event). The lake-effect band weakened with no significant further development over Lake Ontario after 0700 UTC 5 January (see Fig. 4d), most likely due to a decrease in background boundary layer relative humidity and increased wind shear according to nearby soundings. The $850-\mathrm{hPa}$ temperatures remained between $-8^{\circ}$ and $-10^{\circ} \mathrm{C}$ throughout the event (see Figs. 3a-d).

\section{b. Vortices embedded within LLAP snowbands}

Misovortices were frequent features noted during the collection of DOW data in this study, often forming along outflow boundaries associated with LLAP lake-effect snowstorms [please see appendix A in Markowski and Richardson (2010) for a review of how to interpret single Doppler radar observations]. The 16 December 2010 storm had a persistent horizontal shear zone along the length of the band as shown in Fig. 5b. Doppler winds along the southern side of the band approached the radar faster than on the northern side. Embedded within this cyclonic shear zone were several vortices with diameters less than $2 \mathrm{~km}$. One of the strongest couplets [located at $(x, y)=(-12$, $2 \mathrm{~km}$ ) in Fig. 5; grid is defined at the top and left sides of the figure] had a delta-V near $15 \mathrm{~m} \mathrm{~s}^{-1}$ over a distance $(D)$ of approximately $0.8 \mathrm{~km}$, resulting in an implied vertical vorticity value of $0.0375 \mathrm{~s}^{-1}\left(=2 \Delta V_{r} / D\right)$. Two other vortices with distinct hook echoes were observed at $(x, y)=(-16$, $5 \mathrm{~km})$ and $(-21,10 \mathrm{~km})$ and are also visible in Fig. $5 \mathrm{a}$. 

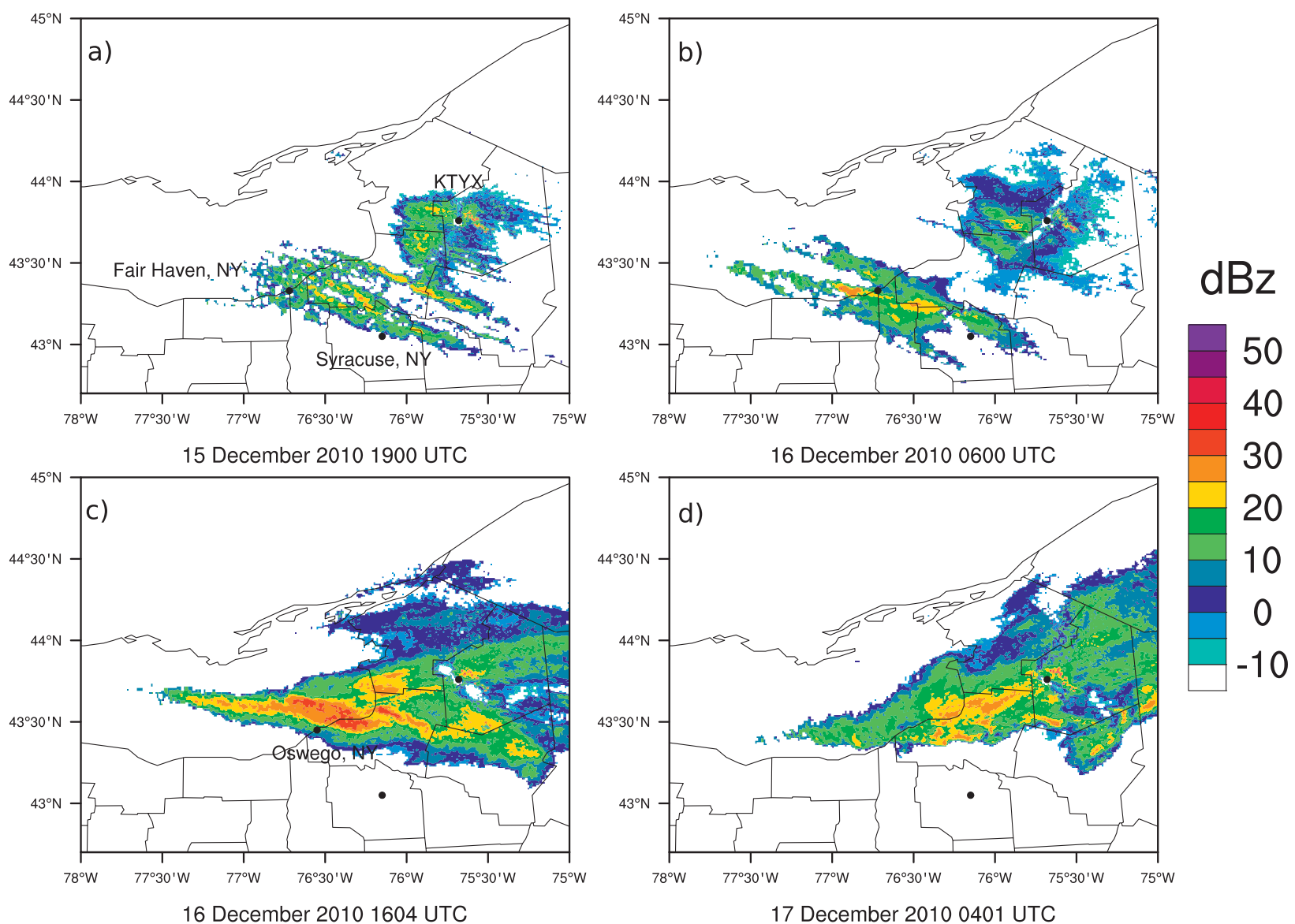

16 December 20101604 UTC

17 December 20100401 UTC

FIG. 2. (a)-(d) Base reflectivity of the 15-16 Dec 2010 lake-effect storm from Montague, NY, WSR-88D (KTYX). Approximate times as shown in Fig. 1. The DOW sampled the storm while in (a),(b) Fair Haven, NY, and (c) in Oswego, NY on the immediate southeast shoreline of Lake Ontario. The location of Syracuse, NY, and the county outlines are also shown.

An outflow boundary originated from and propagated away from the core of the LLAP band on 4 January 2011 at approximately 2130 UTC. Figure $6 \mathrm{~b}$ (note the DOW was just south of the center of the figure) shows an area of implied convergence (note that diagnosed regions of convergence-divergence are based on single Doppler radar data in this study so when analyzed these kinematic properties are always "implied") oriented westsouthwest to east-northeast between points $(-6,8 \mathrm{~km})$ and $(4,12 \mathrm{~km})$. An animation of the reflectivity and Doppler velocity fields is shown in the supplemental file; the top panel of the figure shows the reflectivity and the bottom, the velocity-shows this convergence line propagating to the south, away from the main band reflectivity core, suggesting it was an outflow boundary. The temperature difference across this boundary could not be determined, as no thermodynamic observations were available over the lake. This boundary initiated a line of broken convection as seen in Fig. 6a (cells with reflectivity values $>30 \mathrm{dBZ} 5 \mathrm{~km}$ south of the main snowband at the top of the figure). Misovortices also developed along this outflow boundary; a distinct anticyclonic couplet in Doppler velocity was near $(-1.5,10 \mathrm{~km})$ with suggestions of other vortices forming along the line at $(7,12 \mathrm{~km}$; anticyclonic) and $(0,10 \mathrm{~km}$; cyclonic).

One of the largest vortices (mesoscale) formed later during the 4-5 January 2011 event between 0300 and 0400 UTC, and moved directly over the DOW location from Lake Ontario. The reflectivity field in Fig. 7a shows a swirl pattern centered at $(-27,6 \mathrm{~km})$ associated with the mesovortex. There were smaller hooklike appendages along the southern flank of this main feature that propagated into the center of the vortex. The cyclonic circulation is evident in Fig. 7b; the diameter (using the two velocity extrema closest to each other near $y=4$ and 6 along $x=-26 \mathrm{~km}$ ) was $2.6 \mathrm{~km}$ and the delta- $\mathrm{V}$ was $13 \mathrm{~m} \mathrm{~s}^{-1}$. This feature was contained within a broader circulation with a diameter near $7 \mathrm{~km}$. The Doppler velocity couplets associated with the smaller hook echoes along the south side of the parent vortex were apparent at $(-24,0 \mathrm{~km})$ and $(-22,2 \mathrm{~km})$. 

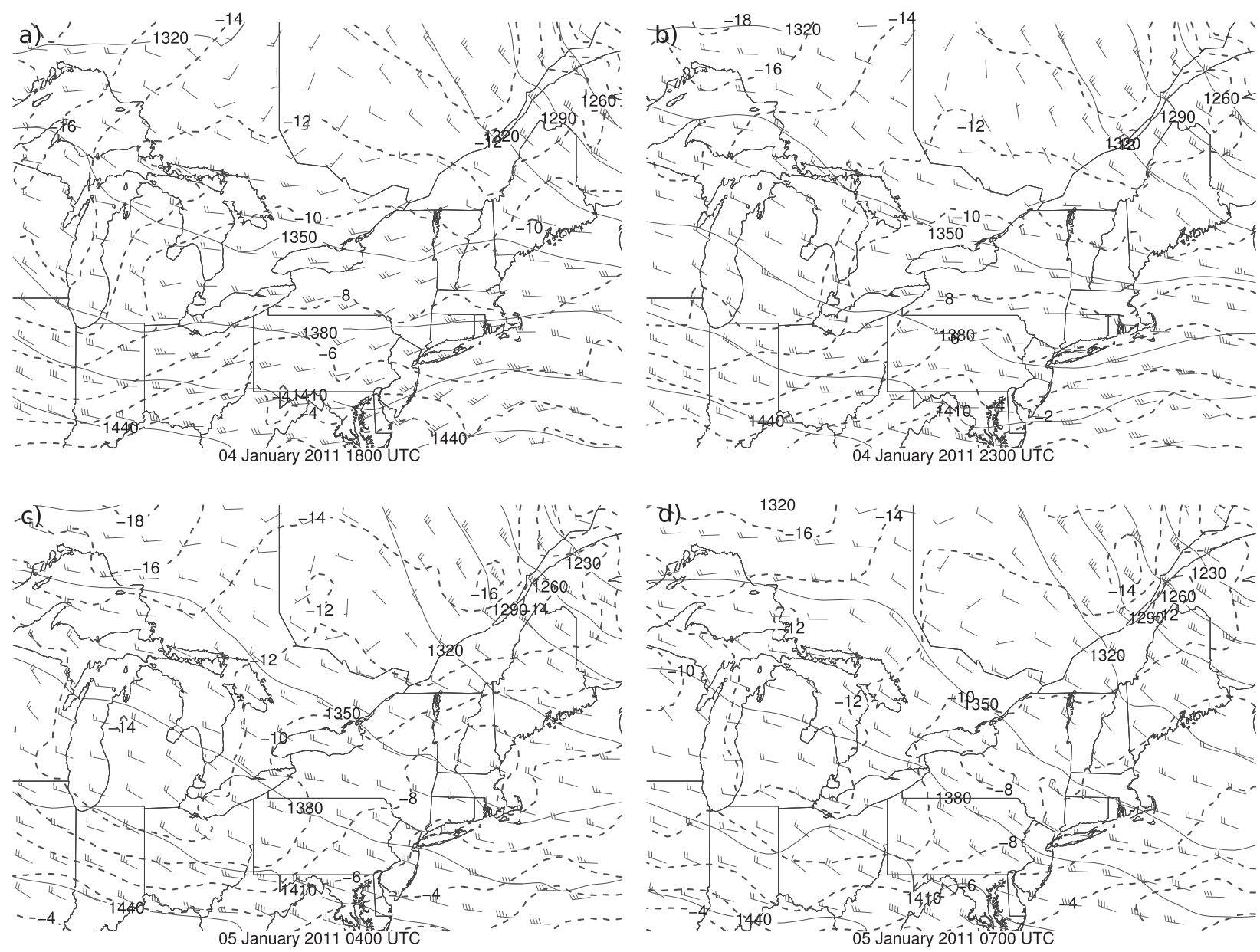

FIG. 3. As in Fig. 1, but for the 4-5 Jan 2011 lake-effect event.

Figures 8 and 9 show the distributions of vortex size and strength for all circulations manually analyzed in every volume scan taken by the DOW for the 16 December 2010 (between 0700-1300 and 1500-1700 UTC) and 4-5 January 2011 (2100-0400 UTC) events. Most of these observations were taken at the lowest elevation scan $\left(1^{\circ}\right)$. Vortex diameter is defined as the distance between Doppler velocity couplet extremes and strength is defined as the Doppler velocity difference between the couplet cores (delta-V; used $1 \mathrm{~m} \mathrm{~s}^{-1}$ resolution). A total of $77 \%(887 / 1158)$ of the vortex observations had diameters less than $1.5 \mathrm{~km}$. Hence, many of these circulations were likely to be undetected by the WSR-88D network. Indeed, the high frequency of observations of distinct vortices, of which only a small sample is shown in Figs. 5-7, was an unexpected find from this research. The delta-V distribution (Fig. 9) had a peak at $11 \mathrm{~m} \mathrm{~s}^{-1}$ and 13 vortices had a delta-V of over $20 \mathrm{~m} \mathrm{~s}^{-1}$. Using the 5 -min criterion (i.e., present in at least two consecutive sector scans) for minimum vortex lifetime and tracking individual vortices through their development led to an estimate of 95 independent vortices that occurred during the analysis period for the 16 December case and 43 vortices during the 4-5 January case (hence, the 1158 observations shown in Figs. 8 and 9 comprised 138 independent vortices).

\section{c. Signatures in the DOW RHI scans}

One of the structures we expected to observe in the vertical cross sections across the minor axis of a LLAPtype band was low-level convergence, a mesoscale updraft, and divergence aloft as shown in other studies (e.g., Peace and Sykes 1966; Ballentine et al. 1998). Figure 10 shows an example from the 16 December 2010 case when the DOW sampled the shorter axis of a LLAP band in which the center of maximum reflectivity was approximately $15 \mathrm{~km}$ to its northeast (Fig. 10a). The Doppler velocity field, however, shows the greatest lowlevel convergence was $10 \mathrm{~km}$ from the DOW, or on the south side of the band (Fig. 10d). There does not appear to be a distinct mesoscale updraft, but more like an overrunning situation implied by the velocity field in 

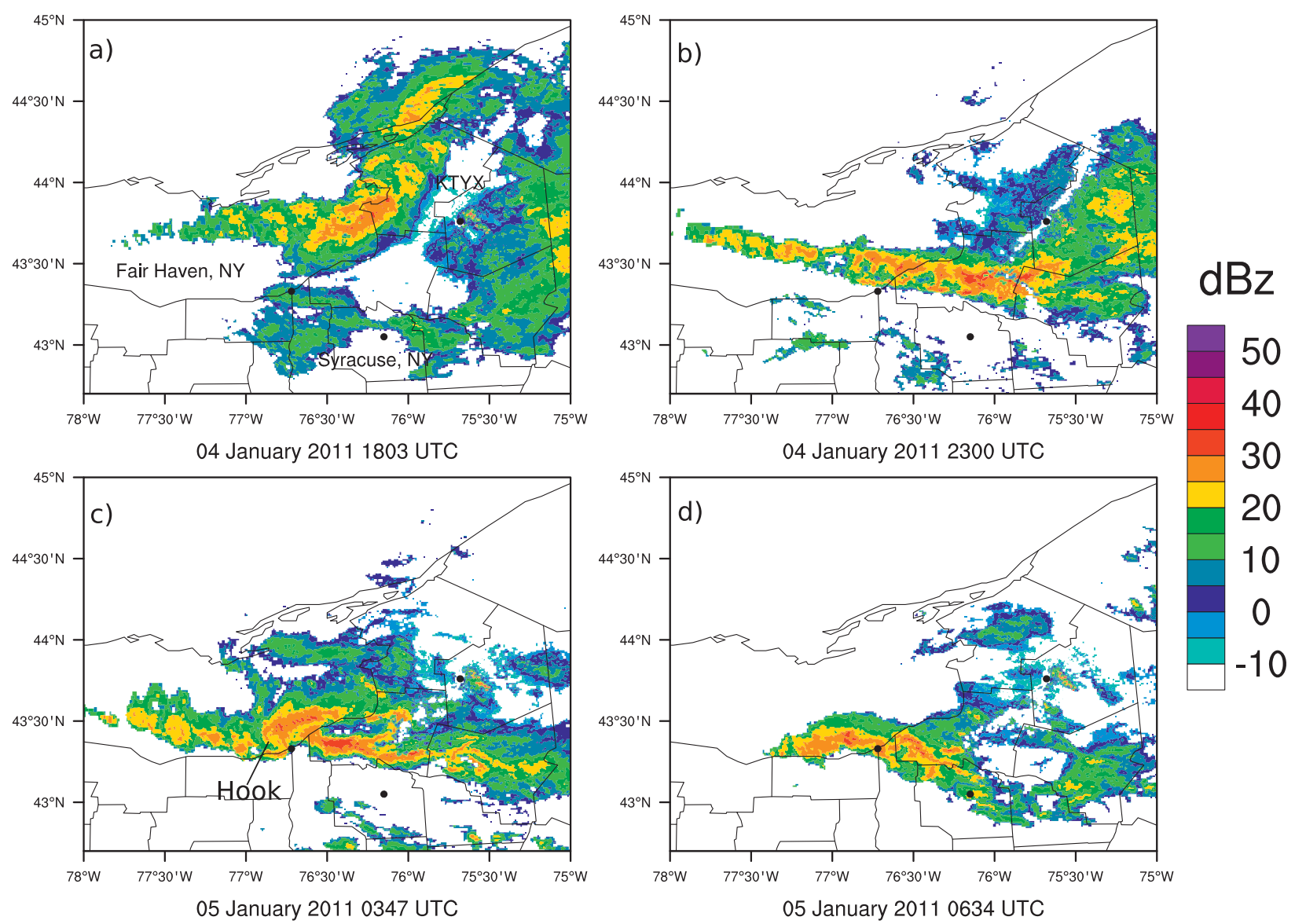

FIG. 4. As in Fig. 2, but for the 4-5 Jan 2011 lake-effect event. The DOW sampled this storm from Fair Haven, NY; and each panel corresponds to the approximate times of the panels in Fig. 3.

which flow from the south ascended over low-level northerly flow (see arrows in Fig. 10d). There is a suggestion of return flow aloft near the top of the band at a range of $5 \mathrm{~km}$ in Fig. 10d. The band was quite shallow with cloud tops only near $2.7 \mathrm{~km}$ above radar level (ARL). The low-level convergence can be seen clearly in the $1^{\circ}$ PPI scan of Doppler velocity (Fig. 10c) approximately $10 \mathrm{~km}$ to the north-northeast of the DOW, along with the horizontal shear zone extending to the northwest of the DOW discussed in section $4 b$.

An even more complex flow across the short axis of this band type is shown in Fig. 11. The reflectivity field (Fig. 11a) shows a well-organized band about $15 \mathrm{~km}$ in width. A low-level convergence zone was along the southern portion of the band approximately $12 \mathrm{~km}$ north of the DOW (Fig. 11c), denoted as a scalloped pattern in the velocity field of receding-near zero radial motion transitioning into incoming motion (as range increases) from azimuth $315^{\circ}$ to $0^{\circ}$ and strongly receding transitioning into weakly receding motion from azimuth $5^{\circ}$ to $50^{\circ}$. The RHI of the reflectivity field (Fig. 11b) shows a mostly uniform distribution, except for an elevated reflectivity core of greater than $30 \mathrm{dBZ}$ on the south side of the band at a range of $12 \mathrm{~km}$, associated with the strongest low-level convergence shown in Fig. 11c. The Doppler velocity RHI scan (Fig. 11d) shows three-layer flow between 13 and $23 \mathrm{~km}$ from the radar. Between a range of 13 and $17 \mathrm{~km}$, there was low-level incoming Doppler velocity below $0.5 \mathrm{~km}$ ARL, receding flow between 0.5 and $2 \mathrm{~km}$, and incoming flow at storm top. The opposite pattern occurred on the northern side of this band $(+,-,+$ Doppler velocity). An updraft can be inferred in Fig. 11d at a range of $17 \mathrm{~km}$ between 0.75 and $2 \mathrm{~km}$ ARL from the nearly vertical stripe of near $0 \mathrm{~m} \mathrm{~s}^{-1}$ Doppler velocity. As a result of these patterns, there were two areas of low-level convergence near the ground at ranges of 12 and $21 \mathrm{~km}$ (south and north edges of the band) and a broader area of midlevel convergence centered at a range, height of (17, $1 \mathrm{~km}$ ARL), followed by outflow aloft at the top of the band.

There were multiple occurrences of bounded weak echo region (BWER; Phillips 1973) signatures throughout 


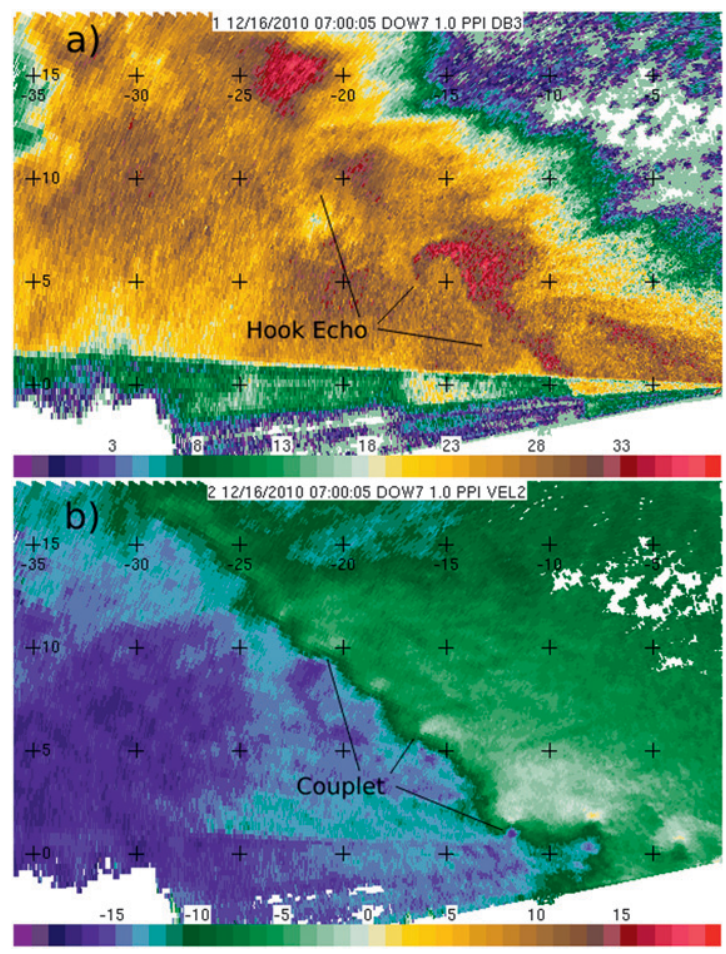

FIG. 5. DOW observations of (a) radar reflectivity $(\mathrm{dBZ})$ and (b) Doppler velocity $\left(\mathrm{m} \mathrm{s}^{-1}\right)$ at 0700:05 UTC 16 Dec 2010 within a lake-effect storm band. Tick marks are every $5 \mathrm{~km}$ from the DOW on a west-east, south-north grid (the radar location is near the bottom-right-hand corner of the image). The reflectivity and velocity color bar labels are located above each bar. Note the radar beam blockage, shown as a sharp gradient along a line, at the bottom of (a).

these two events (e.g., Fig. 12b). A weak echo hole was near $8-\mathrm{km}$ range at $0 \mathrm{~km}$ ARL and extended upward to $1 \mathrm{~km}$ ARL. Figure $12 \mathrm{~d}$ shows this BWER was within an area of low-level convergence. This feature was part of several convective cells forming along the southern flank of the main band (Figs. 12a,c). Stronger low-level convergence and the development of a line of convective cells along the southern flank of the lake-effect band was a frequent occurrence during the DOW observations. Figure 13 shows an exception to this trend; the development of the strongest convective cells (according to maximum reflectivity and band-top height) was on the northern side of the storm in both Figs. 13a,b. Figure $13 \mathrm{c}$ shows two low-level convergence zones north of the DOW at ranges of 13 and $20 \mathrm{~km}$. Note that Fig. 13 was an observation at 2106 UTC 4 January 2011 while Fig. 12 was from 2241 UTC 4 January (approximately $1.5 \mathrm{~h}$ later) showing how structures in a lake-effect band can be quite transient. These figures reveal the complex structures within a band at a given time and through the band's evolution; the greatest

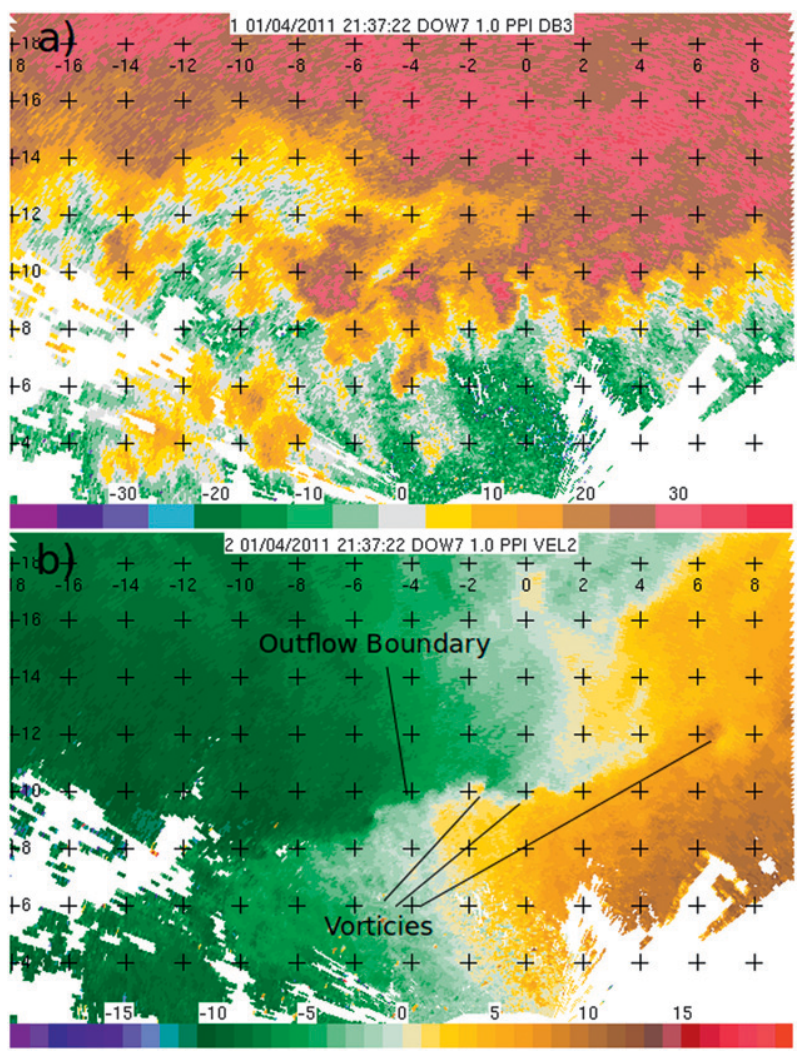

FIG. 6. As in Fig. 5, but for 2137:22 UTC 4 Jan 2011 and tick marks every $2 \mathrm{~km}$. The radar is located immediately right of center toward the bottom of the figure.

reflectivity values and low-level convergence were commonly not in the geometric center of the LLAP lakeeffect band.

The 3.5-h radar reflectivity and Doppler velocity animation from the 4-5 January 2011 event (see supplemental figure) showed an outflow boundary propagating southward and away from the lake-effect band core. This boundary was associated with the BWER shown in Fig. 12. A new line of intense convective elements developed along this boundary within $10 \mathrm{~km}$ of the DOW between 2252 and 2320 UTC 4 January. The convective line developed a "braided" appearance (most distinct at 2252 UTC with a thin line of weaker reflectivity embedded in the line) and a distinct circulation also formed around 0000 UTC 5 January on this line (several other circulations are apparent in the velocity field near this line throughout the animation). The circulation had a distinct hook echo with swirling reflectivity bands and a distinct Doppler velocity couplet as it moved within $5 \mathrm{~km}$ of the DOW at 0012 UTC 5 January.

Figure 14b shows an RHI of a feature similar in appearance to a thunderstorm anvil at a range of $7 \mathrm{~km}$ from the DOW. The reflectivity echo associated with this 

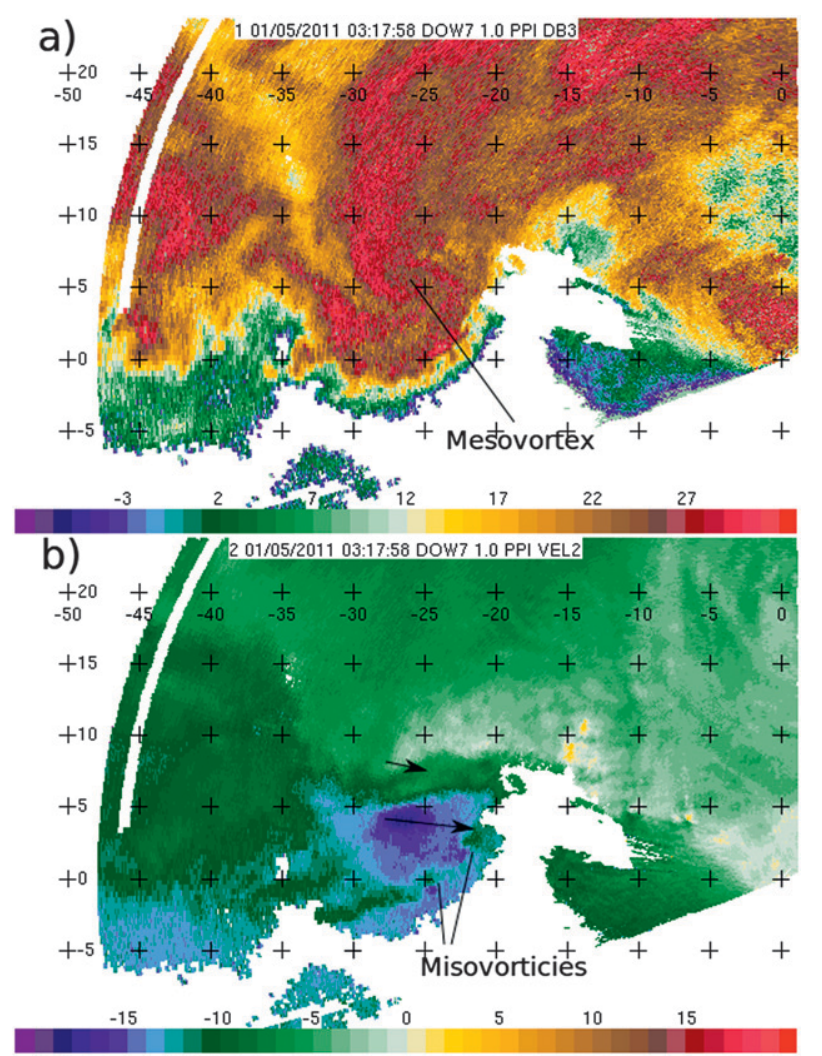

FIG. 7. As in Fig. 5, but for 0317:58 UTC 5 Jan 2011. Please note the reflectivity contour interval is $1 \mathrm{dBZ}$, and the radar is located toward the bottom-right-hand corner of the image.

feature extended to $4 \mathrm{~km}$ ARL while on either side of it the reflectivity extended to only $2 \mathrm{~km}$ ARL. The Doppler velocity field (Fig. 14d) shows inbound values beneath this feature within $0.5-1 \mathrm{~km}$ ARL, which is surprising because of the lack of strong low-level convergence beneath the anvil. The velocity field at the top of the anvil shows upper-level divergence, as one might expect. There was convergence centered at approximately $2 \mathrm{~km}$ ARL $8 \mathrm{~km}$ from the DOW where stronger outbound velocity values decreased with range, which might have caused the upward protrusion of reflectivity and the anvil. A hook echo is also apparent centered north-northeast of the DOW at 2-km range in Fig. 14a. The velocity field shows strong cyclonic rotation in this same region (delta-V near $15 \mathrm{~m} \mathrm{~s}^{-1}$; Fig. 14c).

Horizontal vortices (circulations about a horizontal axis) were observed on the south side of lake-effect storm bands. Figure $15 \mathrm{~b}$ shows an example of one, centered at a range, height of (11, $1 \mathrm{~km}$ ARL). The Doppler velocity field (Fig. 15d) shows the circulation clearly with inbound above outbound velocities separated by a band of $0 \mathrm{~m} \mathrm{~s}^{-1}$ between 7 - and $12-\mathrm{km}$ range at $1 \mathrm{~km}$ ARL. The horizontal vortex formed in the early stages of the aforementioned animation. The outflow boundary was approximately $10-15 \mathrm{~km}$ from the DOW as seen as a line of low-level convergence in Fig. 15c (this convergence is also shown in Fig. 15d near the ground). Another horizontal vortex is visible in Figs. 14b,d approximately $1 \mathrm{~km}$ from the DOW [note the spiral band of weak reflectivity (near $15 \mathrm{dBZ}$ ) on the south side of a convective cell in Fig. 14b and the near $0 \mathrm{~m} \mathrm{~s}^{-1}$ Doppler velocity above the stronger outbound motion in Fig. 14d].

Regions of enhanced Doppler velocity (jets) also occurred within these bands. Figure 16 shows a mesovortex about to propagate over the DOW (a hook echo was within 10-km range to the west-northwest). Inbound motion was located on the southern flank of the hook just within the DOW's field of view (Fig. 16c). A

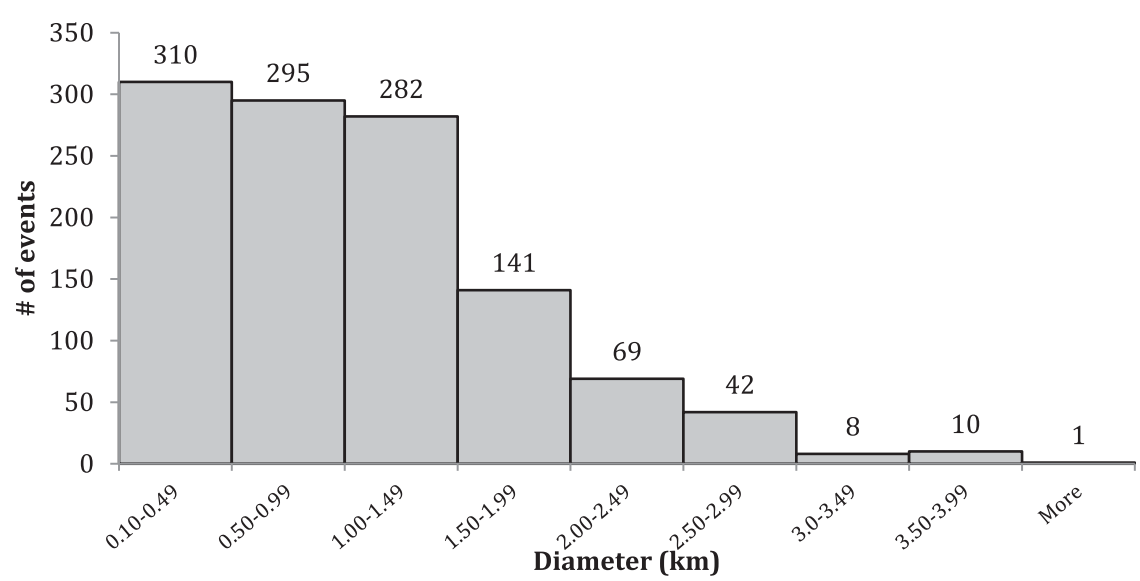

FIG. 8. The diameter distribution for all vortices observed by the DOW and manually analyzed (including observations of the same vortex sampled at different times) between 07001300 and 1500-1700 UTC 16 Dec and between 2100 UTC 4 Jan and 0400 UTC 5 Jan 2011. 


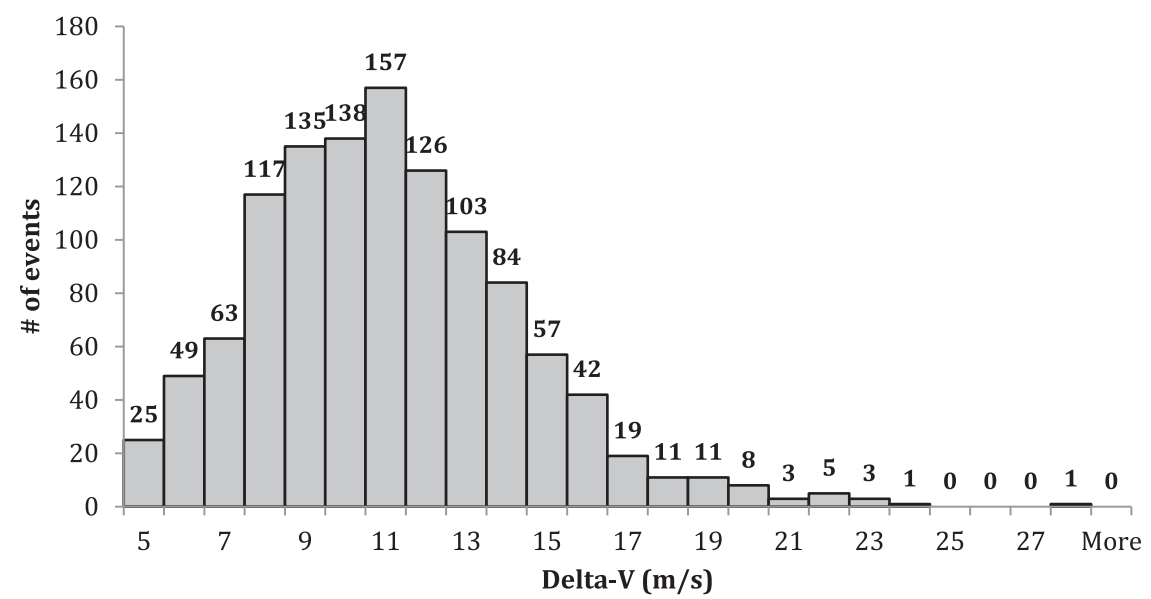

FIG. 9. As in Fig. 8, but for the delta-V.

significant elevated inbound Doppler velocity maximum occurred within the midlevels of this storm centered at a range, height of (10, $1.5 \mathrm{~km}$ ARL; Fig. 16d). Doppler velocity values approached $16 \mathrm{~m} \mathrm{~s}^{-1}$ within the core of this jet. The storm band completely changed position and character after this mesovortex moved inland.

\section{Discussion}

\section{a. Vortex development}

The 15-16 December 2010 event had many more vortex observations (899; 95 independent) compared to the 4-5 January 2011 event (259; 43 independent). There was a $45 \%$ greater chance of observing vortices in the

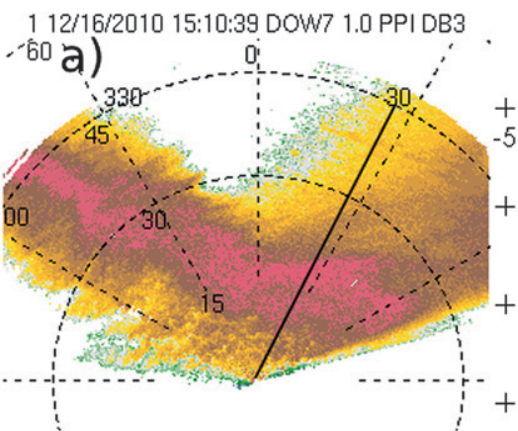

$-30$

b)

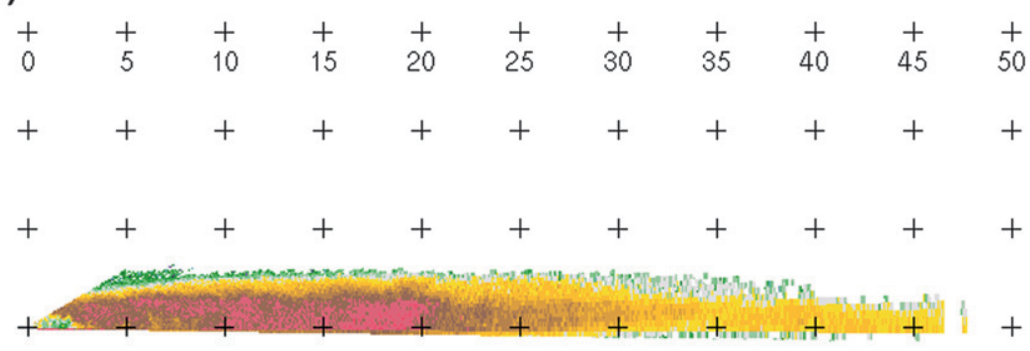

$-10$

0

10

20

30

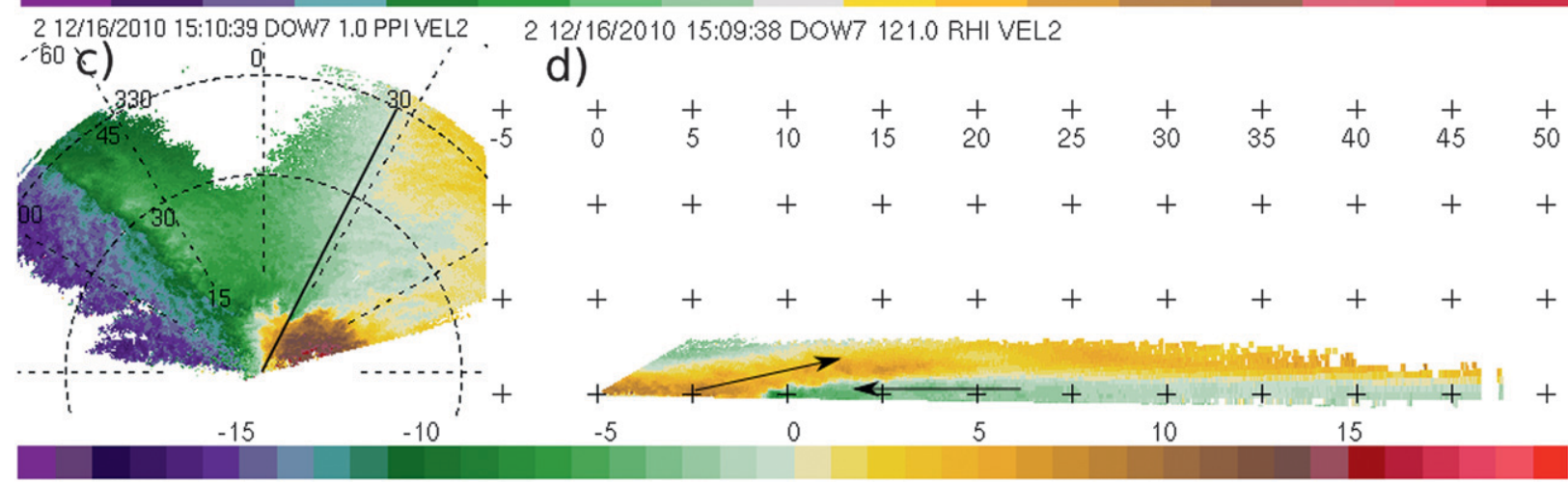

FIG. 10. (a) DOW radar reflectivity (dBZ) PPI and (b) RHI displays of a lake-effect storm. (c),(d) Corresponding Doppler velocity $\left(\mathrm{m} \mathrm{s}^{-1}\right)$ displays from approximately 1510 UTC 16 Dec 2010. Black lines on the PPI imagery show approximate locations of the RHIs. Range rings $(\mathrm{km})$ and azimuthal lines ( ${ }^{\circ}$ from the north) are shown in the PPIs while tick marks $(\mathrm{km})$ are shown in the RHIs relative to the DOW (horizontal and vertical tick intervals are the same). Arrows in the RHI in (d) depict radial flow. The reflectivity and velocity color bar labels are located directly above each bar. 


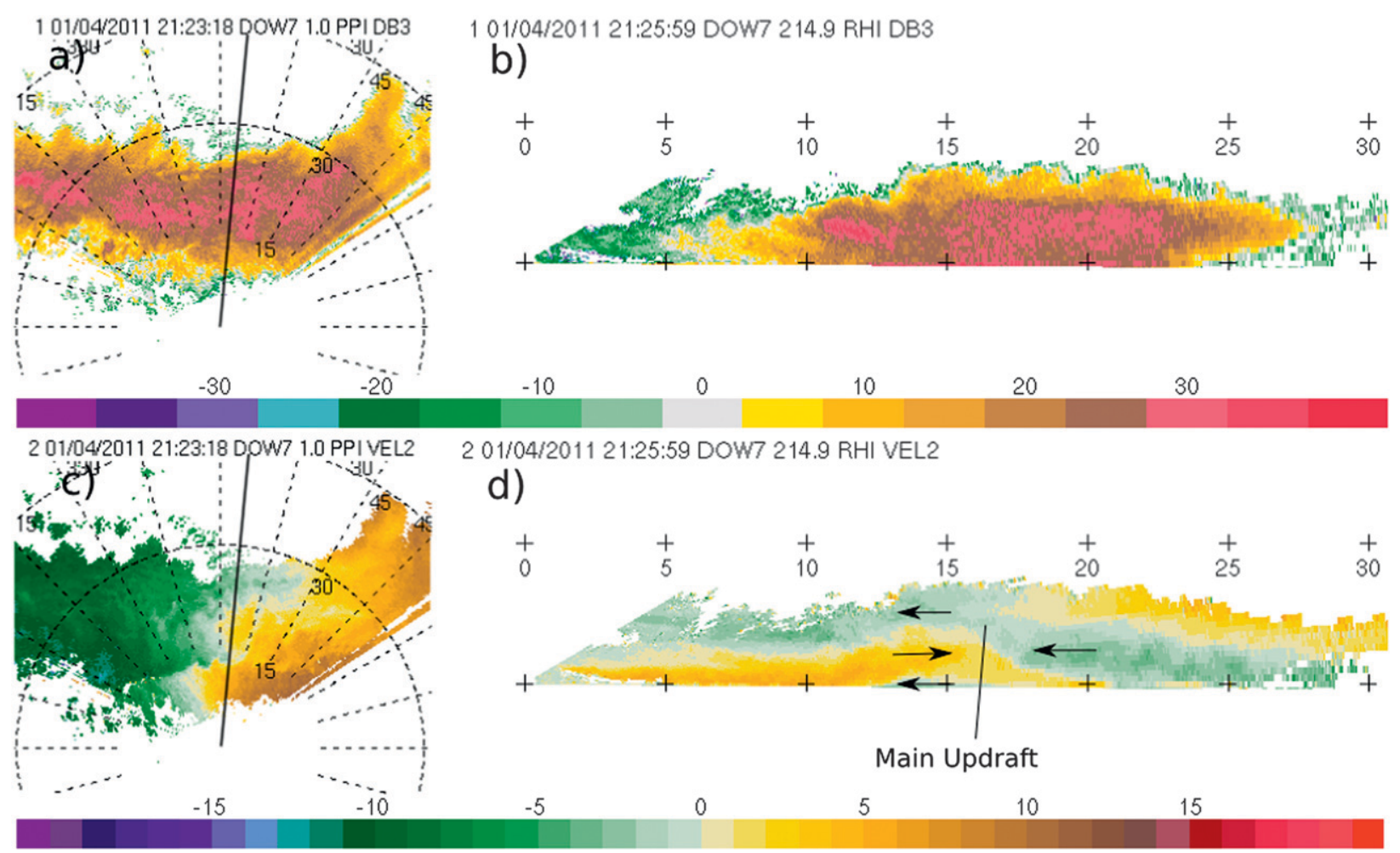

FIG. 11. As in Fig. 10, but for 2123:18 UTC (PPI)/2125:59 UTC (RHI) 4 Jan 2011.

December case due to differences in scan strategies between these cases $\left(1591^{\circ}\right.$ PPIs vs 110 for the January case) even though the analysis time periods were the same (about $8 \mathrm{~h}$ each case). Adjusting for this possibility (multiply the number of vortices observed in the January case by 1.45) leads to 376 vortex observations possible for the January case, still well below the number observed in the December case (899). The number of independent vortices was also much greater for the December case after adjustment (95 vs 62). The mean diameter and strength (delta-V) of the circulations were also notably greater (more than a factor of 2 for the diameter) in the December case. Distinct differences in the degree of instability and depth of the boundary layer occurred between the two cases. The lake surface -850 -hPa temperature difference was approximately $20^{\circ} \mathrm{C}$ throughout much of the December event and only about $14^{\circ} \mathrm{C}$ in the January storm. The greater instability during the December case may have resulted in more vigorous updrafts and hence increased vortex stretching leading to more and stronger vortices. Even though the instability was less during the January storm, there was a deeper, moister boundary layer (top $\sim 575 \mathrm{hPa}, 700 \mathrm{hPa}$ for the December case) based on the upper-air soundings launched at Oswego, New York, near the storm bands. It is uncertain how a shallower boundary layer could lead to a lake-effect snowstorm with more vortices. Indeed, Lee and Wilhelmson (1997) show that environments with deeper neutral layers with respect to outflow depth (i.e., higher capping inversions) are more favorable to misocyclone development.

To better understand how the environment influenced vortex development, the Weather Research and Forecasting (WRF-ARW, version 3.2; Skamarock et al. 2008) modeling system was run in a doubly nested grid formation (horizontal resolutions of $12,4,1.33 \mathrm{~km}$ ) in which the inner grid covered the eastern two-thirds of Lake Ontario and adjacent land areas. This was done as there were insufficient observations available and the RUC data were too coarse (Figs. 1 and 3) to show lowlevel airflow patterns over the lake. The model was initialized at 0000 UTC 16 December 2010 and 1200 UTC 4 January 2011. It performed an excellent simulation of band placement and development when compared to WSR-88D data for both cases. For the December case, the number of observed vortices peaked between 0900 and 1000 UTC 16 December. In the simulation, the background flow transitioned from a northwesterly to more westerly regime at the surface and $850 \mathrm{hPa}$ (see Fig. 1) during and after this time period. The WRF simulation showed that the lake-effect snowband moved northward and developed intense cells. A distinct wind 


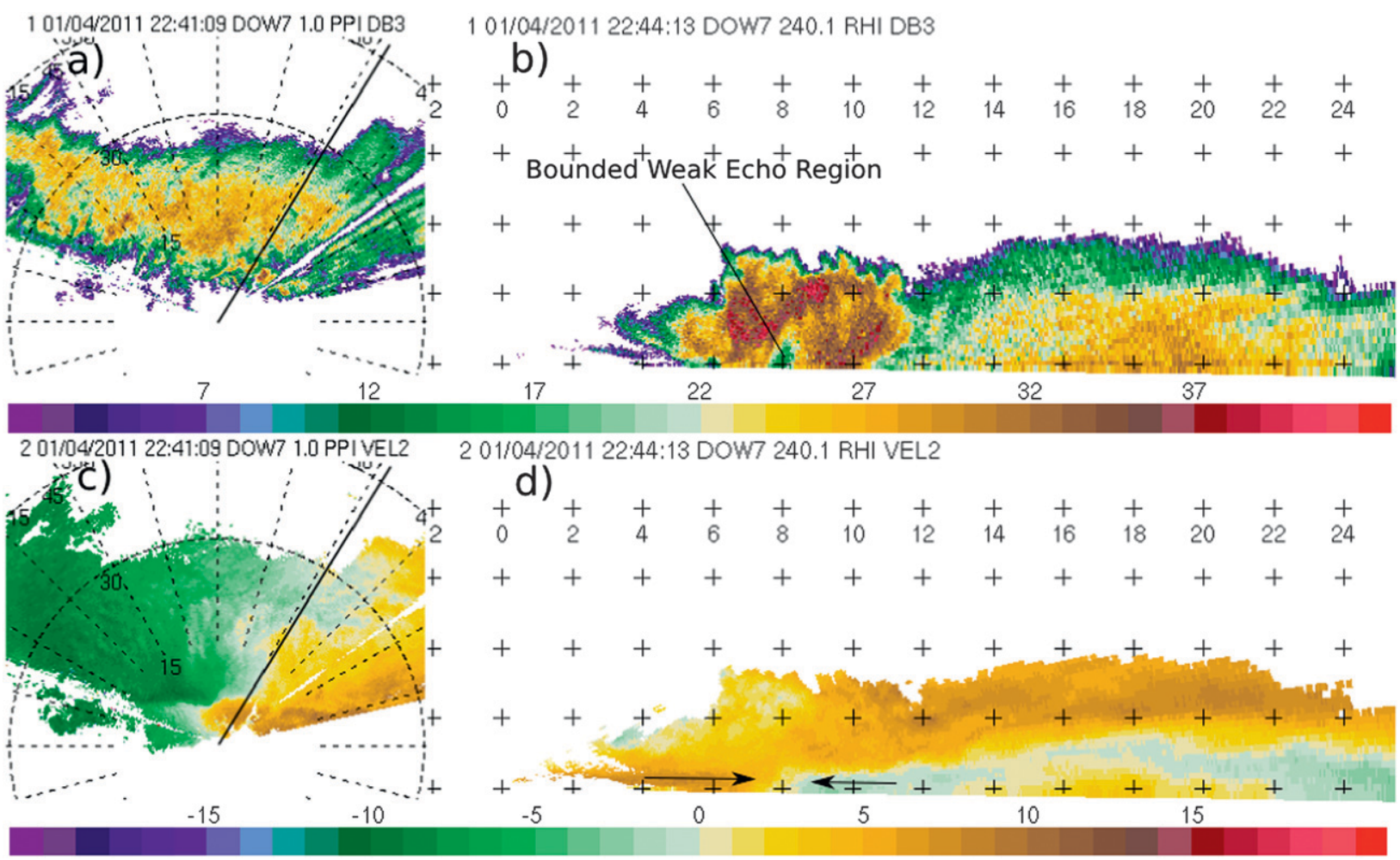

FIG. 12. As in Fig. 10, but for 2241:09 UTC (PPI)/2244:13 UTC (RHI) 4 Jan 2011.

shift was present at $10 \mathrm{~m}$ AGL; the surface winds were westerly approaching $15 \mathrm{~m} \mathrm{~s}^{-1}$ south of the band and were northwesterly at $5 \mathrm{~m} \mathrm{~s}^{-1}$ north of the band at 1000 UTC (Fig. 17) showing strong horizontal shear.

The number of observed vortices in the 4 January 2011 case peaked between 2200 and 2300 UTC. The simulated surface winds were west-southwest at approximately $7.5 \mathrm{~m} \mathrm{~s}^{-1}$ south of the band and northwesterly at $5 \mathrm{~m} \mathrm{~s}^{-1}$ to its north during this period (not shown). This peak in vortex observations occurred in association with the outflow boundary and the subsequent development of a new line of convection along it as discussed in section 4. A background flow transition also occurred during this event between 0300 and 0500 UTC 5 January. A large mesovortex (Fig. 7) developed during this transition from westerly to more northerly flow.

Pease et al. (1988) and Grim et al. (2004) discuss the development of mesovortices that formed over Lake Michigan. The vortices in the current study are significantly smaller than those studied by Grim et al. and Pease et al. $(D \sim 1$ vs $20 \mathrm{~km})$. They investigated several hypotheses for vortex formation including topographical influences (e.g., lake shape), strong horizontal shear across a boundary, and land-breeze fronts intersecting horizontal convective rolls with resultant vortex tilting.
However, Grim et al. concluded it was not possible to determine the cause of the vortices in their cases and stated more detailed research is required to study how and why these vortices develop because they have significant impact on lake-effect snowfall distribution. It is also important to note the synoptic-scale flow was much weaker in their cases $\left(<8 \mathrm{~m} \mathrm{~s}^{-1}\right)$ and a strong land breeze developed; both of these characteristics were absent or not very evident in the 15-16 December 2010 and 4-5 January 2011 cases.

A recent study by Inoue et al. (2011) discusses lowlevel misocyclone development in a Japanese winter storm. These events are typically referred to as seaeffect storms as they form in a similar situation to lakeeffect storms (cold air moving over the relatively warmer waters of the Sea of Japan). The misocyclones in that study also developed along a low-level convergence line, but the parent storm cells were more scattered in nature and not in a linear band as in the current study. The vortex diameters were similar in size to the ones discussed in this paper, ranging from 400 to $2400 \mathrm{~m}$, but they were stronger with delta- $\mathrm{V}$ values between 18 and $36 \mathrm{~m} \mathrm{~s}^{-1}$. This could be due to the stronger shear in the environment and the fact the storms in the Inoue et al. study were taller ( $\sim 6 \mathrm{vs} \sim 3.5 \mathrm{~km}$ in the current study) and hence likely had more vigorous updrafts leading to 


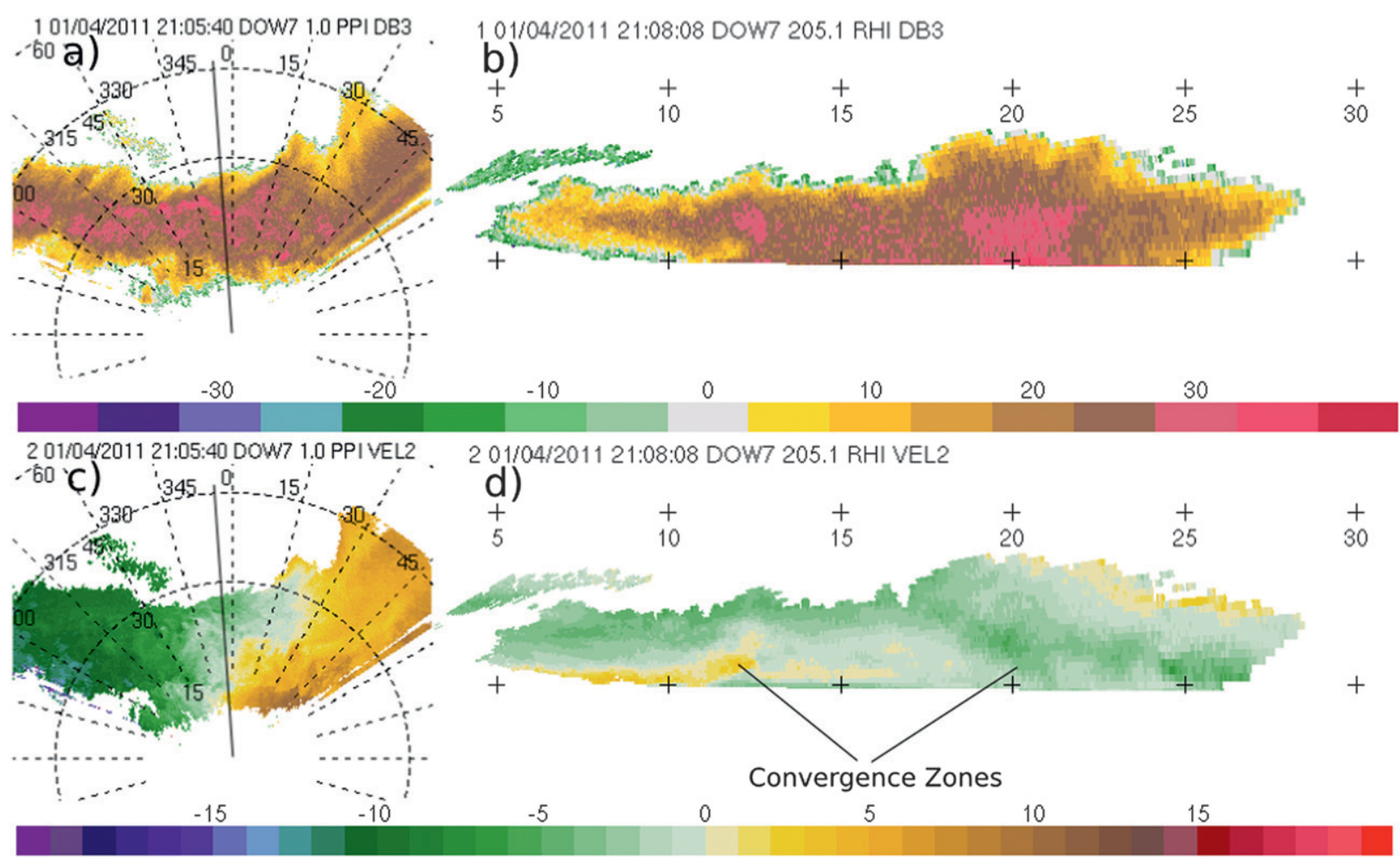

FIG. 13. As in Fig. 10, but for 2105:40 UTC (PPI)/2108:08 UTC (RHI) 4 Jan 2011.

greater tilting and stretching effects on the vertical vorticity.

Lee and Wilhelmson (1997) simulated misocyclone initiation and development along the leading edge of an outflow boundary moving eastward into a southerly flow regime. The simulations from both events in our study are comparable to the Lee and Wilhelmson situation, just rotated $90^{\circ}$ clockwise (northerly intersecting westerly flow). The horizontal shear instability across the boundary led to the development of misocyclones along the boundary in the Lee and Wilhelmson simulation, with regular spacing of 1.6 to $3.2 \mathrm{~km}$ between vortices, similar to the observations discussed herein (see Figs. 5 and 6 , and the supplemental animated figure). Based on these comparisons, we believe horizontal shear instability (Markowski and Richardson 2010, 58-64) is the reason for most of the vortices observed in the lakeeffect bands of this study.

Figure 18 shows a conceptual model of misocyclones forming along a boundary according to Lee and Wilhelmson (1997). Their results suggest these misocyclones can induce vertical motions and develop new deep moist convection. There was a distinct correlation between a misocyclone and the intensification of a secondary band of convection south of the main lake-effect snowband between 2255:05 and 2324:32 UTC 4 January (see supplemental animated figure). The circulation is shown as a very tight couplet at azimuth, range $\left(300^{\circ}, 10 \mathrm{~km}\right)$ at 2255 UTC 4 January. A west-east band of a braided reflectivity structure over $30 \mathrm{dBZ}$ developed along the outflow boundary, with reflectivity maxima associated with the misocyclone as it traveled eastward along the band. It was impossible to determine if the misocyclone caused the convective updrafts via the mechanism described by Lee and Wilhelmson (Fig. 18) that resulted in the intense cells of this band or if the intense updrafts of these cells stretched the vertical vorticity to create/maintain/strengthen the misocyclone. The misocyclone did appear to precede the development of greater reflectivity values between 2302:05 and 2305:35 UTC, supporting the ideas of Lee and Wilhelmson.

Wakimoto and Wilson (1989) discuss an observational study of nonsupercell tornadoes in Colorado that formed along convergence boundaries. They hypothesize that vertical stretching by convective updrafts of preexisting vertical vorticity produced by shearing instability along the boundary is the key factor explaining tornado development in their cases. Radar-detected vortices associated with the tornadoes in the Wakimoto 


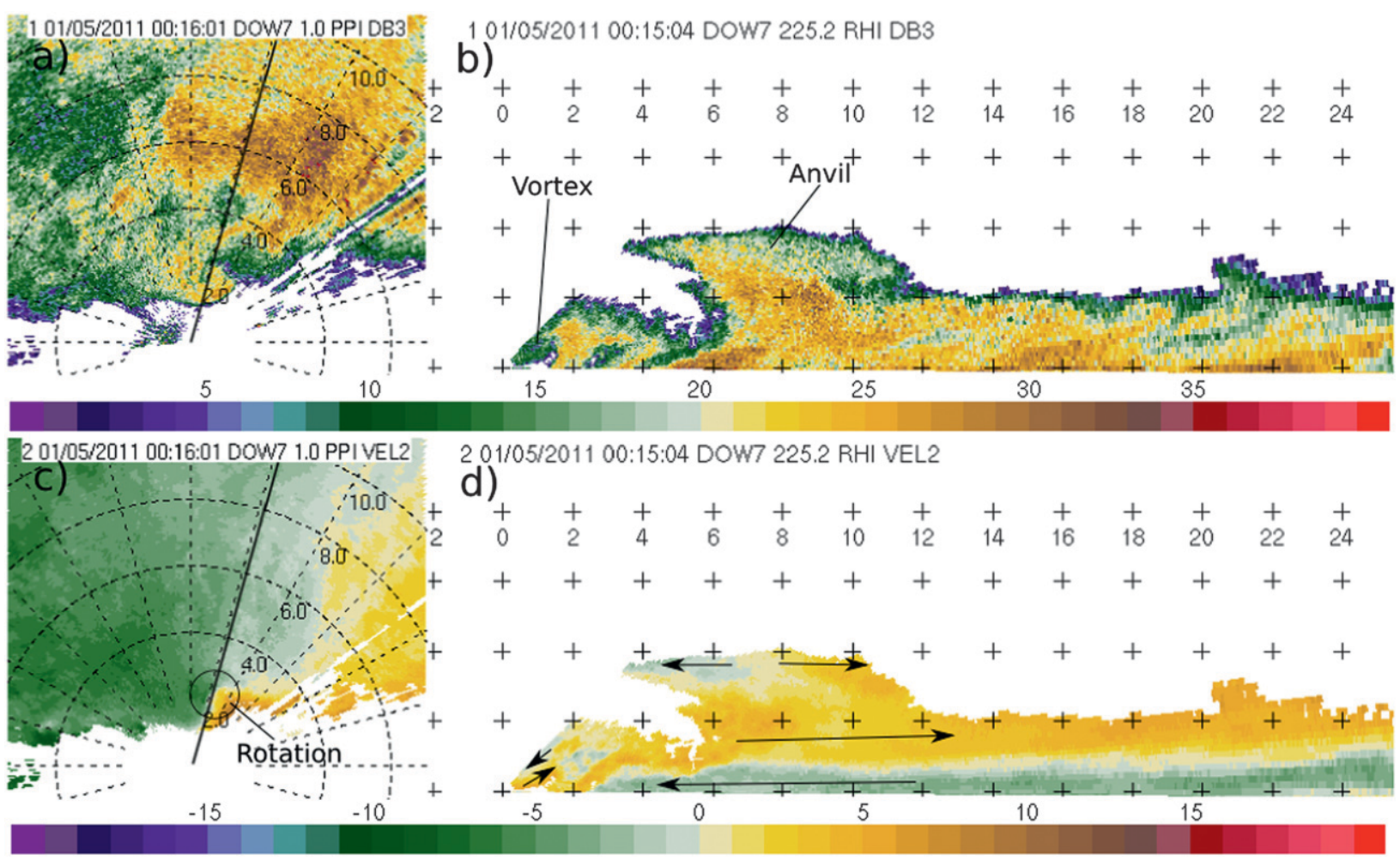

FIG. 14. As in Fig. 10, but for 0016:01 UTC (PPI)/0015:04 UTC (RHI) 5 Jan 2011.

and Wilson study were typically less than or equal to $2 \mathrm{~km}$ in diameter with vorticity values between 20 and $320 \times 10^{-3} \mathrm{~s}^{-1}$, similar to the findings in this study. It is very likely waterspouts were associated with some of the lake-effect misocyclones observed by the DOW (some circulations were observed at $1^{\circ}$ elevation angles within $5 \mathrm{~km}$ of the DOW resulting in an elevation on the order of 200-300 m ARL), even though their existence cannot be confirmed visually as most of the observations were taken at night and snowfall likely obscured any visual appearance.

It should be noted that both the 15-16 December 2010 and 4-5 January 2011 cases featured a shear zone bounded by stronger westerly winds on the southern side of the west-northwest-east-southeast-oriented band (according to the WRF simulation; the in-band Doppler velocity field in Fig. 5 also supports stronger westerly momentum air within the southern half of the storm). We believe this wind field can be explained by the development of a surface thermal low pressure (shown in the sea level pressure field in our WRF results) over the lake that forms in response to the large temperature contrast between the air modified by the warmer lake surface and the polar air mass over adjacent land areas. The LLAP lake-effect storms generally (and in these cases) form over the eastern Great Lakes when a synoptic-scale low pressure system is to the north of the lakes with a southward-directed pressure gradient (this pattern develops the background westerly winds necessary to steer the storm along the lake's long axis; Niziol et al. 1995). The development of a mesoscale, elongated thermal low (seen in our WRF simulations and by Peace and Sykes 1966) stretching west-to-east over Lake Ontario within this synoptic-scale pressure gradient can weaken the gradient over the northern half of the lake and intensify it across the southern half (low pressure develops nearer higher pressure). An LLAP lake-effect band can further increase this pressure gradient on its south side as our simulations have shown the band to be warm core because of latent and sensible heating. Indeed, Peace and Sykes (1966) show from detailed microbarograph studies of a similar band type over Lake Ontario that "all pressure analyses showed a distinctly stronger pressure gradient south of the snow band than north." A mobile mesonet transect performed between 0700 and 0900 UTC 16 December 2010 revealed a pressure drop of nearly $5 \mathrm{hPa}$ between the south side and core of the lake-effect snowband (uncorrected for elevation changes, but these were $\sim 10 \mathrm{~m}$ ). These pressure fields can result in greater westerly momentum to the south of 

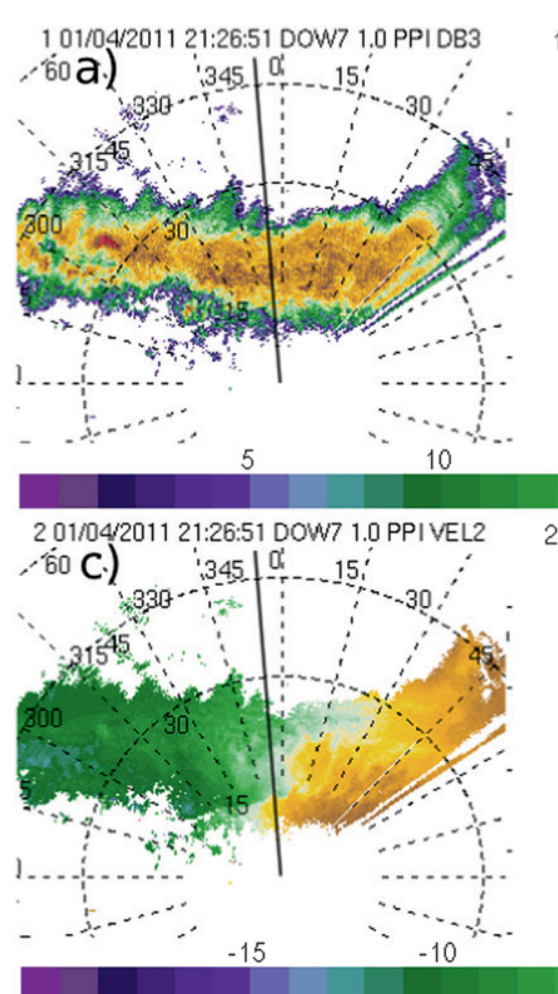

\section{01/04/2011 21:29:18 DOW7 205.1 RHI DB3}

b)

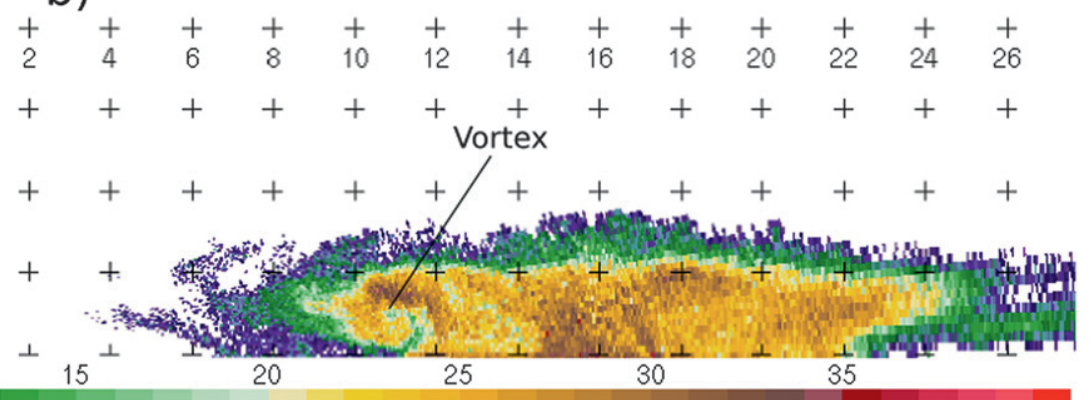

2 01/04/2011 21:29:18 DOW7 205.1 RHI VEL2

d)

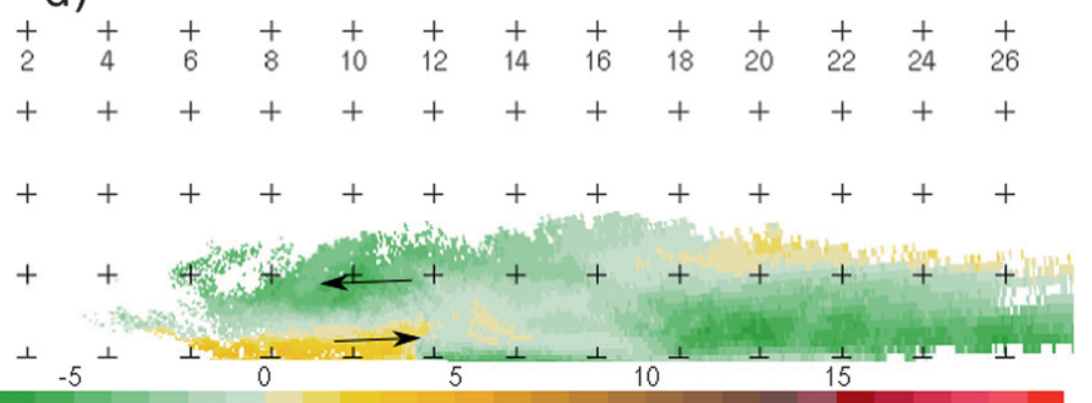

FIG. 15. As in Fig. 10, but for 2126:51 UTC (PPI)/2129:18 UTC (RHI) 4 Jan 2011.

the band through geostrophic adjustment and create the shear zones observed during this study. Future research should investigate the mesoscale temperature and pressure fields when misovortices form under similar conditions as in this study to confirm these fields make it favorable for horizontal shear instability to develop along the convergence boundary that forms under these bands.

\section{b. Radar sampling effects on vortex diameter and delta-V estimates}

The statistics compiled of vortex diameter and strength (measured as change in Doppler velocity between couplet cores; delta-V) are shown in Figs. 8 and 9 without any correction for range effects. For example, a Doppler radar can increasingly underestimate the magnitude of the Doppler velocity in vortex couplet cores with range because of increases in beam sampling volume. Wood and Brown (1992, 1997, 2000) discuss these effects and methods for obtaining truer diameter and velocity estimates in vortices.

To understand the effect of range on the DOW measurements, we plotted average measured vortex diameter and delta- $\mathrm{V}$ versus range in $10-\mathrm{km}$ increments (over 1000 observations using both cases; not shown). The diameter showed a steady increase with range from near 0.5 to $1.8 \mathrm{~km}$ between the $0-10-\mathrm{km}$ range bin and the $40-50-\mathrm{km}$ bin. This was a concern as it is consistent with beam spreading effects. However, after using the correction factor for estimating true core diameter suggested by Wood and Brown [(1992), their Eq. (15)], the changes in these diameter measurements were small $(<5 \%)$ and the trend of increasing diameter with range remained the same. The mean delta- $\mathrm{V}$ measurements showed a more surprising result for these cases as they increased with range from near 10.8 to $11.7 \mathrm{~m} \mathrm{~s}^{-1}$. Range degradation on velocity measurements is expected to have the opposite effect (e.g., see Figs. 6 and 7 in Wood and Brown 1997). Based on the above information, we decided to show the raw measurements of vortex diameter and delta- $\mathrm{V}$, as their variations were likely more influenced by meteorological factors, not range effects. It is noted that the appendix in Inoue et al. (2011) describes a method for correcting vortex core diameter and tangential velocity measurements and will be possibly tested on these data in the future.

\section{c. Vertical structure of LLAP bands}

The flow in the vertical plane across the short axis of a LLAP lake-effect storm is asymmetrical, with the major mesoscale updraft typically off-center toward the 


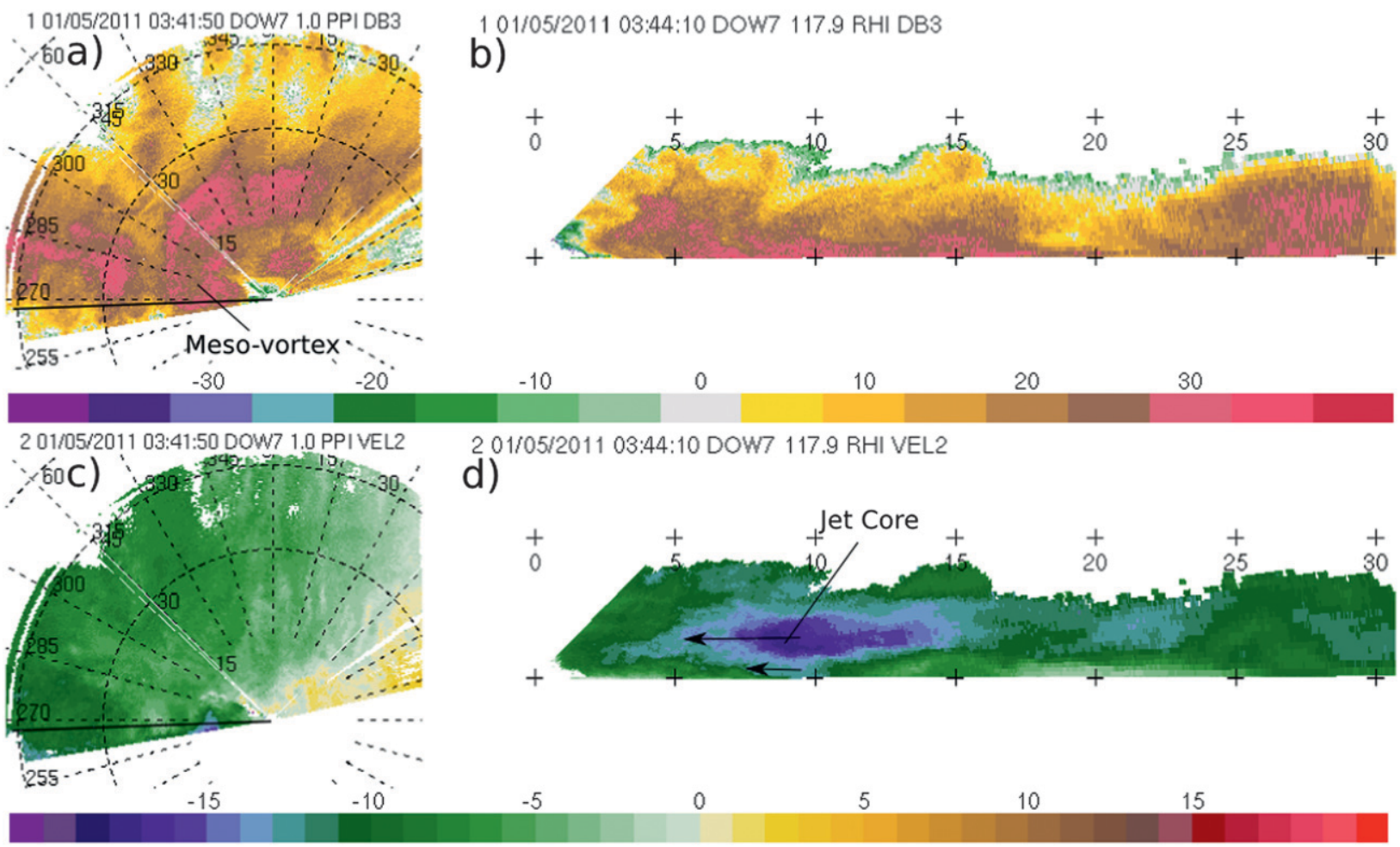

FIG. 16. As in Fig. 10, but for 0341:50 UTC (PPI)/0344:10 UTC (RHI) 5 Jan 2011.

southern side of the band (e.g., Fig. 10). The vertical motion is more similar to the overrunning process used to explain lift along a warm front. Figure 10 depicts an example of what was typically observed with these events: southerly flow moving up and over northerly flow across a west-east-oriented band. A similar structure, although on a larger scale, was apparent for an oceanic warm front observed by airborne radar in Wakimoto and Bosart (2001). An important question arises: what was the temperature structure over the lake (i.e., was the northerly flow crossing the lake colder than the overrunning southerly flow as expected in a warm frontal situation)? Some WRF modeling results from this and other similar lake-effect storms (not shown) show the air to the south is colder as it is not modified by a warm lake. Future observational and modeling studies are needed to address this discrepancy.

The occasional occurrence of BWER (e.g., Fig. 12), overshooting tops (e.g., Figs. 13 and 14), and horizontal vortices (e.g., Fig. 15) was a surprise finding in the DOW observations. The lake-effect BWERs were much shallower than those observed with supercellular convection (top of BWER in Fig. 12 near $1 \mathrm{~km}$ vs near $7-10 \mathrm{~km}$ in supercells; e.g., Knight 1984). These features typically formed on the south side of the storm bands in regions dominated by convective motions (e.g., approximately vertical updrafts denoted by a vertical stripe of near $0 \mathrm{~m} \mathrm{~s}^{-1}$ Doppler velocity and areas of local maxima in reflectivity). A hypothesis for the presence of more convection on the south side of these bands is the possible existence of enhanced gravitational instability in this region of the band. The warmest lake surface temperatures are usually in the southeast region of Lake Ontario, where the water is at its deepest (see http://www.ngdc.noaa.gov/mgg/greatlakes/lakeontario_ cdrom/html/gmorph.htm), leading to the enhanced instability as cold air moves over this water. The horizontal vortices can be explained by the strong vertical shear induced by return flow over inflow as in Fig. 15d.

\section{Conclusions}

The analysis presented herein of high-resolution Doppler on Wheels (DOW) observations of long-lakeaxis-parallel (LLAP)-lake-effect storms during the winter of 2010-11 over Lake Ontario has led to the following conclusions and research questions:

- More than 1100 radar volume scans of miso- and mesovortices embedded in LLAP storms were observed within two cases over a combined 15 -h period. These observations comprised 138 independent vortices. The 

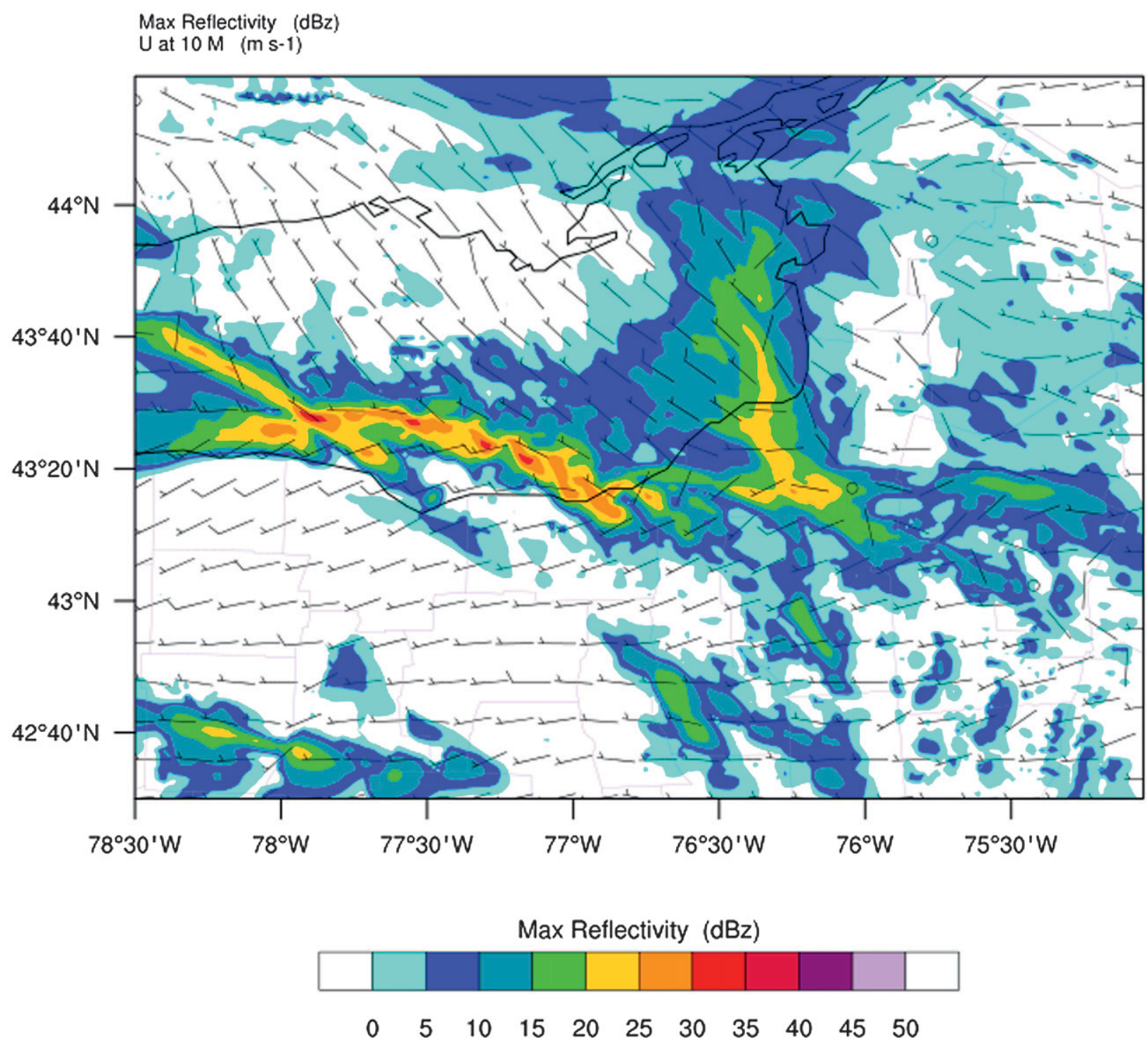

FIG. 17. WRF-ARW simulation of composite reflectivity (dBZ) and 10-m winds (barbs, $\mathrm{m} \mathrm{s}^{-1}$ ) for 1000 UTC 16 Dec 2010 (model initialized at 0000 UTC). The Lake Ontario shoreline is shown and wind barbs are plotted approximately every $6 \mathrm{~km}$.

high frequency of occurrence of vortices in LLAP bands is a new find and more research is needed to determine if these are outlier events or common to most of these storms. The cause for these circulations is likely horizontal shear instability, created by an enhanced mesoscale pressure gradient to the south of the west-east (sometimes west-northwest-east-southeast) oriented band, which produces stronger westerly flow interacting with weaker northwesterly flow to the north of the lake-effect band. The mesovortex shown in Fig. 7 affected the storm band behavior by shifting it southward by $\sim 10 \mathrm{~km}$ showing its occurrence has important forecast implications.
- Many interesting features were observed in the DOW's RHI scans across the shorter axes of these LLAP bands, including bounded weak echo regions (BWERs), jets, and horizontal vortices. Most of these features were observed along the west-east-oriented band's southern edge. As with the first conclusion, these were new discoveries in LLAP bands and require future research.

- There was an asymmetrical structure in which the strongest updraft region and/or largest reflectivity values with greatest vertical extent were displaced to the south or north of the west-east band's geometrical core. A LLAP band commonly did not have the 


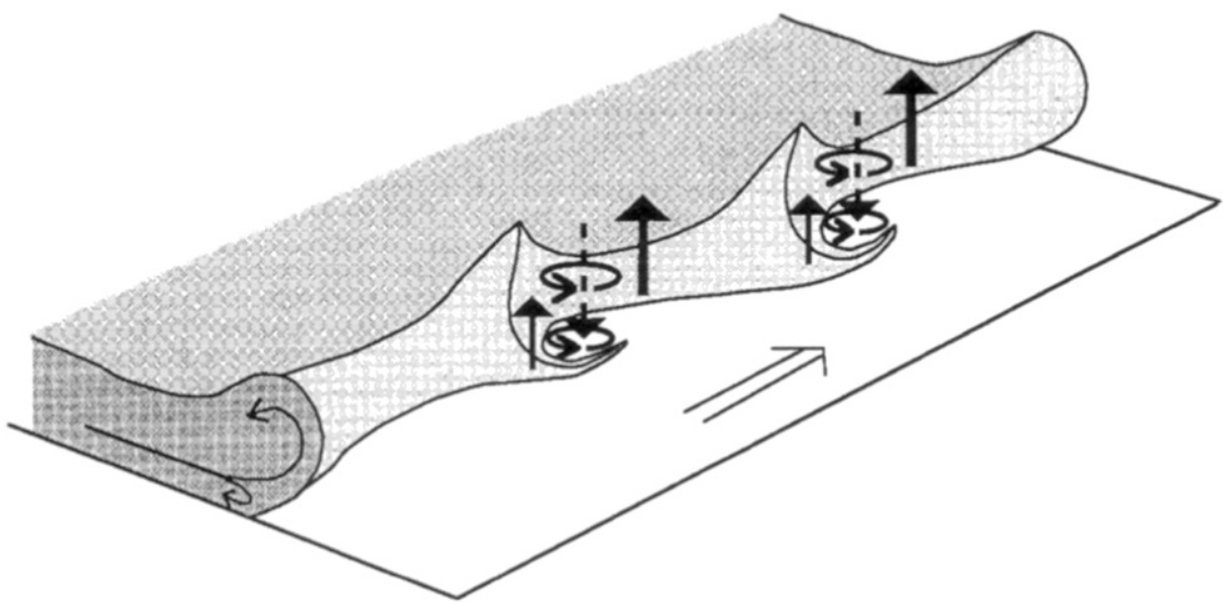

FIG. 18. Diagram from Lee and Wilhelmson (1997) showing how misocyclones form along an outflow boundary. Broad arrow ahead of the density current shows background southerly flow interacting with eastward-advancing boundary. Misocyclone-induced vertical motions are also shown.

expected [from studies such as Peace and Sykes (1966) and Ballentine et al. (1998)] classic transverse "in, up, and out" flow field. Indeed, there were cases of warmfront-like structures within the bands and an outflow boundary initiating a new, stronger line of convection to the south of the main band.

- Thermodynamic measurements are needed to test the hypotheses for shear zone and vortex development, especially over the lake. Aircraft radar and in situ observations would be ideal. More observations are needed of the boundaries shown in this study; we know little about their origin and thermal characteristics (e.g., cold outflow).

Acknowledgments. We thank the DOW crews, which were supported by National Science Foundation Grant AGS-0724318. There were several SUNY Oswego undergraduate research assistants who helped collect the data, including Evan Duffey, Joseph Finlon, Brittany Gibbons, Jake Mulholland, and Lacey Pitman. We also thank all reviewers of this manuscript for providing insight on improving its science and presentation. This research is supported by the National Science Foundation under Grant AGS-1042826.

\section{REFERENCES}

Ahasic, E. T., J. W. Frame, and T. R. Cermak, 2012: Classification of precipitation types in lake-effect snow events using dualpolarimetric Doppler radar observations. Preprints, 16th Symp. on Meteorological Observation and Instrumentation, New Orleans, LA, Amer. Meteor. Soc., P6.4. [Available online at https:/ams.confex.com/ams/92Annual/webprogram/Paper199189. html.]
Ballentine, R. J., and D. Zaff, 2007: Improving the understanding and prediction of lake-effect snowstorms in the eastern Great Lakes region. Final Rep. to the COMET Outreach Program Award S06-58395, 41 pp.

— A. J. Stamm, E. E. Chermack, G. P. Byrd, and D. Schleede, 1998: Mesoscale model simulation of the 4-5 January 1995 lake-effect snowstorm. Wea. Forecasting, 13, 893-920.

Cermak, T. R., J. W. Frame, and E. T. Ahasic, 2012: Dual-polarization observations of vortices and cellular convection within lakeeffect snow bands. Preprints, 16th Symp. on Meteorological Observation and Instrumentation, New Orleans, LA, Amer. Meteor. Soc., P6.6. [Available online at https://ams.confex. com/ams/92Annual/webprogram/Paper199211.html.]

Fujita, T. T., 1981: Tornadoes and downbursts in the context of generalized planetary scales. J. Atmos. Sci., 38, 1511-1534.

Grim, J. A., N. F. Laird, and D. A. R. Kristovich, 2004: Mesoscale vortices embedded within a lake-effect shoreline band. Mon. Wea. Rev., 132, 2269-2274.

Hjelmfelt, M. R., 1992: Orographic effects in simulated lake-effect snowstorms over Lake Michigan. Mon. Wea. Rev., 120, $373-$ 377.

Holroyd, E. W., III, 1971: Lake-effect cloud bands as seen from weather satellites. J. Atmos. Sci., 28, 1165-1170.

Inoue, H. Y., and Coauthors, 2011: Finescale Doppler radar observation of a tornado and low-level misocyclones within a winter storm in the Japan Sea coastal region. Mon. Wea. Rev., 139, 351-369.

Kelly, R. D., 1982: A single Doppler radar study of horizontal-roll convection in a lake-effect storm. J. Atmos. Sci., 39, 15211531.

Knight, C. A., 1984: Radar and other observations of two vaulted storms in northeastern Colorado. J. Atmos. Sci., 41, 258-271.

Kristovich, D. A. R., and R. A. Steve III, 1995: A satellite study of cloud-band frequencies over the Great Lakes. J. Appl. Meteor., 34, 2083-2090.

— ment and the snow band dynamics project. Bull. Amer. Meteor. Soc., 81, 519-542.

Laird, N. F., J. E. Walsh, and D. A. R. Kristovich, 2003: Model simulations examining the relationship of lake-effect morphology 
to lake shape, wind direction, and wind speed. Mon. Wea. Rev., 131, 2102-2111.

Lee, B. D., and R. B. Wilhelmson, 1997: The numerical simulation of non-supercell tornadogenesis. Part I: Initiation and evolution of pretornadic misocyclone circulations along a dry outflow boundary. J. Atmos. Sci., 54, 32-60.

Markowski, P., and Y. Richardson, 2010: Mesoscale Meteorology in the Midlatitudes. Wiley-Blackwell, $407 \mathrm{pp}$.

Moore, P. K., and R. E. Orville, 1990: Lightning characteristics in lake-effect thunderstorms. Mon. Wea. Rev., 118, 17671782.

Niziol, T. A., 1987: Operational forecasting of lake effect snowfall in western and central New York. Wea. Forecasting, 2, 310321.

— W. R. Snyder, and J. S. Waldstreicher, 1995: Winter weather forecasting throughout the eastern United States. Part IV: Lake effect snow. Wea. Forecasting, 10, 61-77.

Oye, R., C. Mueller, and S. Smith, 1995: Software for radar translation, visualization, editing, and interpolation. Preprints, 27th Conf. on Radar Meteorology, Vail, CO, Amer. Meteor. Soc., 359-363.

Passarelli, R. E., Jr., and R. R. Braham Jr., 1981: The role of the winter land breeze in the formation of Great Lake snow storms. Bull. Amer. Meteor. Soc., 62, 482-491.

Peace, R. L., Jr., and R. B. Sykes Jr., 1966: Mesoscale study of a lake effect snow storm. Mon. Wea. Rev., 94, 495-507.

Pease, S. R., W. A. Lyons, C. S. Keen, and M. Hjelmfelt, 1988: Mesoscale spiral vortex embedded within a Lake Michigan snow squall band: High resolution satellite observations and numerical model simulations. Mon. Wea. Rev., 116, 13741380.
Phillips, B. B., 1973: Precipitation characteristics of a sheared, moderate intensity, supercell-type Colorado thunderstorm. J. Appl. Meteor., 12, 1354-1363.

Reinking, R. F., and Coauthors, 1993: The Lake Ontario Winter Storms (LOWS) project. Bull. Amer. Meteor. Soc., 74, 1828-1849.

Skamarock, W. C., and Coauthors, 2008: A description of the advanced research WRF version 3. NCAR Tech. Note NCAR/ TN-4751STR, 88 pp.

Stumpf, G. J., A. Witt, E. D. Mitchell, P. L. Spencer, J. T. Johnson, M. D. Eilts, K. W. Thomas, and D. W. Burgess, 1998: The National Severe Storms Laboratory mesocyclone detection algorithm for the WSR-88D. Wea. Forecasting, 13, 304-326.

Wakimoto, R. M., and J. W. Wilson, 1989: Non-supercell tornadoes. Mon. Wea. Rev., 117, 1113-1140.

_ a warm front during FASTEX. Mon. Wea. Rev., 129, 254-274.

Wood, V. T., and R. A. Brown, 1992: Effects of radar proximity on single-Doppler velocity signatures of axisymmetric rotation and divergence. Mon. Wea. Rev., 120, 2798-2807.

_ , and — 1997: Effects of radar sampling on single-Doppler velocity signatures of misocyclones and tornadoes. Wea. Forecasting, 12, 928-938.

— , and — 2000: Oscillations in mesocyclone signatures with range owing to azimuthal radar sampling. J. Atmos. Oceanic Technol., 17, 90-95.

Wurman, J., 2001: The DOW mobile multiple-Doppler network. Preprints, 30th Int. Conf. on Radar Meteorology, Munich, Germany, Amer. Meteor. Soc., 95-97.

_ _ J. Straka, E. Rasmussen, M. Randall, and A. Zahrai, 1997: Design and deployment of a portable, pencil-beam, pulsed, 3-cm Doppler radar. J. Atmos. Oceanic Technol., 14, 1502-1512. 